University of Texas Rio Grande Valley

ScholarWorks @ UTRGV

Physics and Astronomy Faculty Publications and Presentations

$1-8-2019$

\title{
Electron density topological and adsorbate orbital analyses of water and carbon monoxide co-adsorption on platinum
}

\author{
N. Dimakis \\ The University of Texas Rio Grande Valley \\ Isaiah Salas \\ Luis Gonzalez \\ Neili Loupe \\ Eugene S. Smotkin
}

Follow this and additional works at: https://scholarworks.utrgv.edu/pa_fac

Part of the Astrophysics and Astronomy Commons

\section{Recommended Citation}

Nicholas Dimakis, et. al., (2019) Electron density topological and adsorbate orbital analyses of water and carbon monoxide co-adsorption on platinum.Journal of Chemical Physics150:2. DOI: http://doi.org/ $10.1063 / 1.5046183$

This Article is brought to you for free and open access by the College of Sciences at ScholarWorks @ UTRGV. It has been accepted for inclusion in Physics and Astronomy Faculty Publications and Presentations by an authorized administrator of ScholarWorks @ UTRGV. For more information, please contact justin.white@utrgv.edu, william.flores01@utrgv.edu. 


\section{Electron density topological and adsorbate orbital analyses of water and carbon monoxide co-adsorption on platinum}

Cite as: J. Chem. Phys. 150, 024703 (2019); https://doi.org/10.1063/1.5046183

Submitted: 26 June 2018 . Accepted: 11 December 2018. Published Online: 08 January 2019

Nicholas Dimakis (D), Isaiah Salas (D), Luis Gonzalez (D), Neili Loupe (D), and Eugene S. Smotkin
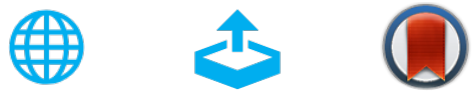

View Online

Export Citation

\section{ARTICLES YOU MAY BE INTERESTED IN}

Adsorption of water, methanol, and their mixtures in slit graphite pores

The Journal of Chemical Physics 150, 024705 (2019); https://doi.org/10.1063/1.5078603

An AIMD study of dissociative chemisorption of methanol on $\mathrm{Cu}(111)$ with implications for formaldehyde formation

The Journal of Chemical Physics 150, 024706 (2019); https://doi.org/10.1063/1.5070129

Optical properties of semiconducting zigzag carbon nanotubes with and without defects

The Journal of Chemical Physics 150, 024701 (2019); https://doi.org/10.1063/1.5055271

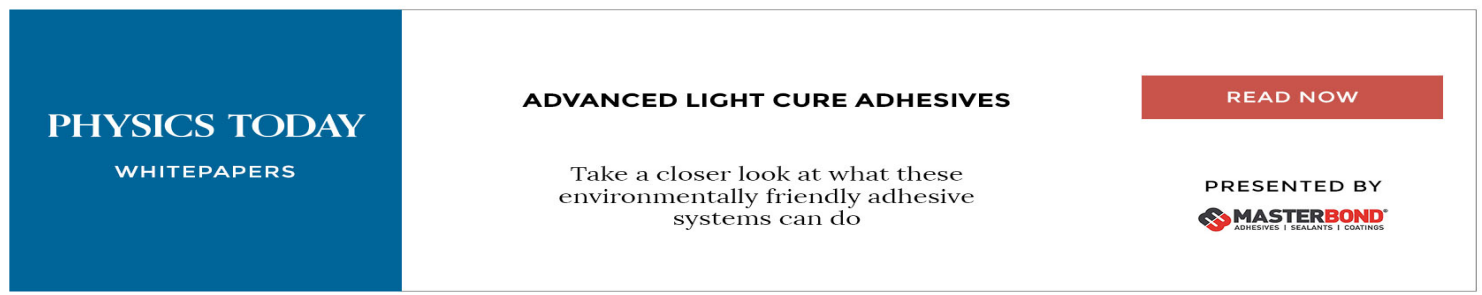




\title{
Electron density topological and adsorbate orbital analyses of water and carbon monoxide co-adsorption on platinum
}

Cite as: J. Chem. Phys. 150, 024703 (2019); doi: 10.1063/1.5046183

Submitted: 26 June 2018 - Accepted: 11 December 2018 •

Published Online: 8 January 2019

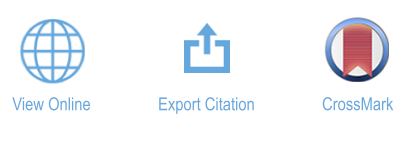

Nicholas Dimakis, ${ }^{1, a)}$ (D) Isaiah Salas, ${ }^{2}$ (D) Luis Gonzalez, ${ }^{3}$ (D) Neili Loupe, ${ }^{4}$ (D) and Eugene S. Smotkin

\author{
AFFILIATIONS \\ ${ }^{1}$ Department of Physics and Astronomy, University of Texas Rio Grande Valley, 1201 W. University Drive, Edinburg, \\ Texas 78539-2999, USA \\ ${ }^{2}$ Achieve Early College High School, McAllen, Texas 78501, USA \\ ${ }^{3}$ PSJA Thomas Jefferson T-STEM Early College HS, Pharr, Texas 78577, USA \\ ${ }^{4}$ Department of Chemistry and Chemical Biology, Northeastern University, Boston, Massachusetts 02115, USA
}

a) Author to whom correspondence should be addressed: nicholas.dimakis@utrgv.edu. Telephone: (956) 665-8761.

\begin{abstract}
The electron density topology of carbon monoxide $(\mathrm{CO})$ on dry and hydrated platinum is evaluated under the quantum theory of atoms in molecules (QTAIM) and by adsorbate orbital approaches. The impact of water co-adsorbate on the electronic, structural, and vibrational properties of $\mathrm{CO}$ on Pt are modelled by periodic density functional theory (DFT). At low CO coverage, increased hydration weakens $\mathrm{C}-\mathrm{O}$ bonds and strengthens $\mathrm{C}-\mathrm{Pt}$ bonds, as verified by changes in bond lengths and stretching frequencies. These results are consistent with QTAIM, the $5 \sigma$ donation- $2 \pi^{*}$ backdonation model, and our extended $\pi$-attraction $\sigma$-repulsion model (extended $\pi-\sigma$ model). This work links changes in the non-zero eigenvalues of the electron density Hessian at QTAIM bond critical points to changes in the $\pi$ and $\sigma \mathrm{C}-\mathrm{O}$ bonds with systematic variation of $\mathrm{CO} / \mathrm{H}_{2} \mathrm{O}$ co-adsorbate scenarios. QTAIM invariably shows bond strengths and lengths as being negatively correlated. For atop CO on hydrated Pt, QTAIM and phenomenological models are consistent with a direct correlation between $\mathrm{C}-\mathrm{O}$ bond strength and $\mathrm{CO}$ coverage. However, DFT modelling in the absence of hydration shows that $\mathrm{C}-\mathrm{O}$ bond lengths are not negatively correlated to their stretching frequencies, in contrast to the Badger rule: When QTAIM and phenomenological models do not agree, the use of the non-zero eigenvalues of the electron density Hessian as inputs to the phenomenological models, aligns them with QTAIM. The C-O and C-Pt bond strengths of bridge and three-fold bound CO on dry and hydrated platinum are also evaluated by QTAIM and adsorbate orbital analyses.
\end{abstract}

Published under license by AIP Publishing. https://doi.org/10.1063/1.5046183

\section{INTRODUCTION}

\section{A. Background}

Carbon monoxide has a greater affinity for fuel cell Pt catalysts than does hydrogen. ${ }^{1}$ This is compounded by the fact that hydrogen fuel cell anode potentials are never sufficiently positive to oxidize adsorbed $\mathrm{CO}\left(\mathrm{CO}_{\text {ads }}\right)$ to $\mathrm{CO}_{2} \cdot{ }^{2}$ Hence, transition metals, alloyed or in mixed phase with $\mathrm{Pt}$, are used to lower the $\mathrm{CO}$ adsorption energy $\left(\mathrm{E}_{\mathrm{ads}}\right)$. This is known as the ligand effect. ${ }^{3}$ In direct methanol fuel cells, where the anode can be as high as $300 \mathrm{mV}$ vs reversible hydrogen electrode (RHE), transition metals (e.g., Ru) lower the activation energy by activating water for oxygen transfer to $\mathrm{CO}_{\text {ads }}$ (Ref. 2). The key components for theoretical analyses of hydrogen and direct oxidation fuel cells are $\mathrm{CO}$, water, and the catalyst structure. . $^{5}$

$\mathrm{CO}$ adsorption on transition metals and alloys are described by phenomenological and catalyst d-band models 
(Nørskov d-band center ${ }^{6}$ and our d-band dispersion ${ }^{7}$ model). The phenomenological models include (1) Blyholder-type models, ${ }^{8}(2)$ the Nilsson and co-workers ${ }^{9-13} \pi$-attraction and $\sigma$-repulsion $(\pi-\sigma)$ model, and most recently (3) the DimakisSmotkin extended $\pi-\sigma$ model. ${ }^{14-17}$

\section{Blyholder-type models}

Upon adsorption on $\mathrm{Pt}$, the internal $\mathrm{CO}_{\text {ads }}$ bond weakens (C-O stretching frequency downshifts) and a stable $\mathrm{C}-\mathrm{Pt}$ bond is formed. ${ }^{18-20}$ This is explained by a $5 \sigma$ donation $-2 \pi^{*}$ backdonation model, also known as the "Blyholder model." The original Blyholder model was limited to $\pi$-molecular orbital contributions to the adsorption process ( $1 \pi$ and $\left.2 \pi^{*}\right)$. The effect of the $5 \sigma$ donation was added later. ${ }^{21}$ Although the $5 \sigma$ donation$2 \pi *$ backdonation model successfully explains $\mathrm{CO}$ adsorption on a variety of metals including $\mathrm{Pt},{ }^{22}$ it fails for $\mathrm{CO}_{\mathrm{ads}}$ on Pt-based alloys. ${ }^{15}$

\section{Nilsson $\pi$-attraction and $\sigma$-repulsion $(\pi-\sigma)$ model}

The Nilsson $\pi-\sigma$ model improves the $5 \sigma$ donation $-2 \pi^{*}$ backdonation model by extension of charge polarization effects over the entire set of $\sigma$ and $\pi \mathrm{CO}$-substrate orbitals. The hybridization of the $\mathrm{CO}$ molecular orbitals with the metal orbitals yields hybrid adsorbate-substrate tilde-type orbitals. The $\tilde{\pi}$-system contains three orbitals/bands: the $1 \tilde{\pi}$, the $d_{\tilde{\pi}}$, and the $2 \tilde{\pi}^{*}$-bands. The $1 \tilde{\pi}$ orbital is both $\mathrm{C}-\mathrm{O}$ and $\mathrm{C}$-metal bonding, whereas the $2 \tilde{\pi}^{*}$-band is $\mathrm{C}-\mathrm{O}$ antibonding and $\mathrm{C}$ metal bonding. The $d_{\tilde{\pi}}$-band is a hybrid of the $1 \pi$ and $2 \pi^{*}$ CO molecular orbitals mixed with the metal $d_{x z, y z}$-band. The $d_{\tilde{\pi}}$-band extends from a lower energy region dominated by oxygen lone pair electrons and heavily weighted by a $1 \pi$ contribution (i.e., $\mathrm{C}-\mathrm{O}$ bonding) to a higher energy region extending to the Fermi level with a heavy $2 \pi^{*}$ contribution (i.e., $\mathrm{C}-\mathrm{O}$ antibonding). While the $\pi-\sigma$ model does not explicitly invoke direct backdonation to the $\mathrm{CO}$ region of the $2 \tilde{\pi}^{*}$, such backdonation is inferred by the presence of the $\mathrm{C}-\mathrm{O}$ antibonding $d_{\tilde{\pi}}$ high energy region that weakens the internal $\mathrm{CO}_{\text {ads }}$ bond. The decreased $1 \tilde{\pi}$ polarization towards oxygen also contributes to the internal $\mathrm{CO}_{\mathrm{ads}}$ bond weakening.

The $\tilde{\sigma}$-system also contains three orbitals/bands: the $4 \tilde{\sigma}$ and $5 \tilde{\sigma}$ orbitals and the $d_{\tilde{\sigma}}$-band. The $4 \tilde{\sigma}$ and $5 \tilde{\sigma}$ orbitals are C-metal bonding, whereas the $d_{\tilde{\sigma}}$-band is C-metal antibonding. Moreover, the $4 \tilde{\sigma}$ and the $d_{\tilde{\sigma}}$-band are $\mathrm{C}-\mathrm{O}$ antibonding, whereas the $5 \tilde{\sigma}$ is weekly bonding. The free $\mathrm{CO} 4 \sigma$ and $5 \sigma$ molecular orbitals are polarized towards oxygen and carbon, respectively. Upon hybridization with metal orbitals, the $4 \tilde{\sigma}$ and $5 \tilde{\sigma}$ orbitals reverse polarization and strengthen the internal $\mathrm{CO}_{\mathrm{ads}}$ bond. The $\pi-\sigma$ model does not consider charge donation from the $\mathrm{CO}$ regions of the $4 \tilde{\sigma}$ and $5 \tilde{\sigma}$ orbitals to the substrate bands. Therefore, the $\tilde{\sigma}$-system is repulsive to the surface. The internal $\mathrm{CO}_{\text {ads }}$ bond weakens upon adsorption because the weakening of the $\tilde{\pi}$-system more than offsets the strengthening of the $\tilde{\sigma}$-system.

\section{Dimakis-Smotkin extended $\pi-\sigma$ model}

The extended $\pi-\sigma$ model considers the same $\tilde{\pi}$-system as does the $\pi-\sigma$ model: The $d_{\tilde{\pi}^{-}}$and $2 \tilde{\pi}^{*}$-bands are equivalent to the $\pi-\sigma$ model $d_{\tilde{\pi}}$-lower energy region and $d_{\tilde{\pi}}$-higher energy region, respectively. The innovation of this model is inclusion of the attractive components of the $\tilde{\sigma}$-system orbitals/bands via donation from the $4 \tilde{\sigma}$ and $5 \tilde{\sigma}$ orbitals to the substrate bands. In the extended $\pi-\sigma$ model, the $\tilde{\sigma}-$ system is $\mathrm{C}$-metal bonding. The $\mathrm{C}$-metal $4 \tilde{\sigma}$ and $5 \tilde{\sigma}$ bonding orbitals are not offset by the antibonding $d_{\tilde{\sigma}}$-band. This was not the case in the original $\pi-\sigma$ model, which assumed that all $\tilde{\sigma}$-system orbitals/bands below the Fermi level were filled (Ref. 11). Incomplete occupancy of the $d_{\tilde{\sigma}}$-band was confirmed by Rangelov et al., using inverse photoemission spectra of $\mathrm{CO} / \mathrm{Ni}, \mathrm{CO} / \mathrm{Pd}$, and $\mathrm{CO} / \mathrm{Pt} .^{23}$ In the extended $\pi-\sigma$ model, the effect of the $5 \tilde{\sigma}$ orbital on the internal $\mathrm{CO}_{\text {ads }}$ bond is small. ${ }^{14}$ The extended $\pi-\sigma$ model has been used by other research groups. $^{24-27}$

We described an expression that correlates changes in $v_{\mathrm{CO}}$ to changes in the $\mathrm{CO}_{\mathrm{ads}}, \mathrm{C}$, and $\mathrm{O}$ atomic orbital charges (Ref. 17). Here we modify the expression for $\mathrm{C}-\mathrm{O}$ stretching frequency from our prior report by including the oxygen contribution to the $2 \tilde{\pi}^{*}$-band as

$$
v_{\mathrm{CO}} \propto-\left(\mathrm{Q}_{\mathrm{O} 2 \mathrm{~s}}^{4 \tilde{\sigma}}+\mathrm{Q}_{\mathrm{C} 2 \mathrm{~s}}^{5 \tilde{\sigma}}+\mathrm{Q}_{\mathrm{C} 2 \mathrm{~s}}^{d_{\tilde{\sigma}}}+\mathrm{Q}_{\mathrm{Cpxy}}^{\tilde{\pi}}+\mathrm{Q}_{\mathrm{Opxy}}^{\widetilde{2 \pi^{*}}}\right)
$$

where $\mathrm{Q}_{y}^{\mathrm{x}}$ are charge contributions of the $y$ atomic orbital to the $x$ tilde-type orbital/band. This expression improves the description of the $\tilde{\pi}$-system, by allowing for charge to be directly transferred between $\mathrm{CO}_{\mathrm{ads}}$ and interacting water molecules.

\section{B. Quantum theory of atoms in molecules (QTAIM) applied to $\mathrm{CO}$ adsorbed on metals}

Phenomenological models based on adsorbate orbital occupation have shortcomings. Orbital charges, obtained by integration of densities-of-states (DOS) spectra, do not always correlate to bond strengths. Bader and co-workers have developed the quantum theory of atoms in molecules (QTAIM), which is based on the topology of $\rho(\vec{r}), \nabla \rho(\vec{r})$, and the Laplacian $\nabla^{2} \rho(\vec{r})$ to describe atoms and bonds of chemical systems. QTAIM analyses are basis set and method independent, as long as a minimally adequate basis set is used. ${ }^{28}$ Figure 1 shows the free CO $\rho(\vec{r})$ and the $\nabla \rho(\vec{r})$ associated with the CO bond critical point. It also shows the negative of the Laplacian $-\nabla^{2} \rho(\vec{r})$ associated with the oxygen and carbon non-bonding charge concentrations (i.e., presence of lone pair electrons). The 2D $\rho(\vec{r})$ and $-\nabla^{2} \rho(\vec{r})$ are plotted with CRYSPLOT. ${ }^{29}$ The AIM-UC program was used to plot and calculate the $3 \mathrm{D} \rho(\vec{r})$ and $-\nabla^{2} \rho(\vec{r})$ and the $\nabla \rho(\vec{r}) .{ }^{30}$ A pair of atoms is considered "bonded," when a point of zero-flux density [Fig. 1(b), black line] along the path connecting these two atoms (bond path) carries charge accumulation in the plane perpendicular to the internuclear axis [Fig. 1(a)]. This point is the bond critical point [saddle point in the 3D $\rho(\vec{r})]$. Moreover, the $-\nabla^{2} \rho(\vec{r})$ is used to determine change accumulation at non-nuclear locations, as in the case of free CO [Fig. 1(c)]. Figure 1(b) shows the atomic basins for carbon and oxygen atoms, which are the regions of space traversed by all $\nabla \rho(\vec{r})$ that terminate at the attractor or nucleus and are bounded by zero-flux surfaces. ${ }^{31}$ 


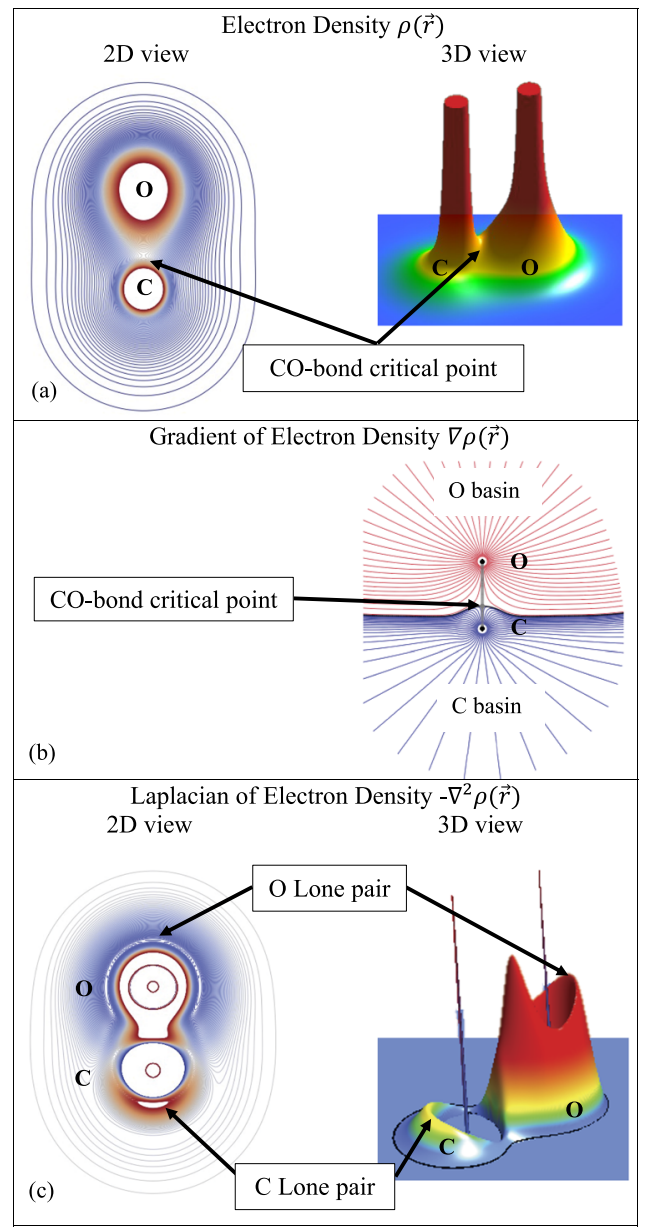

FIG. 1. Free $\mathrm{CO}$ representations with labeled bond critical point and lone pairs (a) extrema electron densities $\rho(\vec{r}): 2 \mathrm{D}$ and 3D (high charge, red; low charge, blue); (b) gradient of electron density $\nabla \rho(\vec{r})$ (oxygen, red; carbon, blue; bond path, gray line; zero flux surface, black line), (c) extrema Laplacian $-\nabla^{2} \rho(\vec{r}): 2 \mathrm{D}$ and $3 \mathrm{D}$ [color code same as (a)].

$\mathrm{CO}$ adsorption on metals has been analyzed by QTAIM. ${ }^{32-37}$ Macchi and Sironi analyzed $\mathrm{CO}_{\text {ads }}$ on $\mathrm{B}, \mathrm{Cr}, \mathrm{Fe}, \mathrm{Co}$, $\mathrm{Ni}$, and $\mathrm{Cu}$ using transition metal-carbonyl clusters (Ref. 37) and emphasized the difficulty of detecting $\pi^{*}$-backdonation due to $\rho(\vec{r})$ cylindrical symmetry for metal-C bonds. However, they did not relate the non-zero eigenvalues of the $\rho(\vec{r})$ Hessian to $5 \sigma$-donation and $2 \pi^{*}$-backdonation between the $\mathrm{CO}$ and the adsorbing metal.

Chemical interactions are also described by Energy Decomposition Analysis (EDA), ${ }^{38,39}$ Constrained Space Orbital Variation (CSOV), ${ }^{40,41}$ Natural Energy Decomposition AnalysisNEDA, ${ }^{42-44}$ localized molecular orbitals EDA, ${ }^{45,46}$ and more recently periodic energy decomposition analysis (pEDA). ${ }^{47}$ EDA has been extended to the study of $\mathrm{CO}_{\text {ads }}$ on metals and metal oxides of Li and Na (Ref. 48), Ni (Ref. 11), Cu (Refs. 11, 48, and 49), $\mathrm{Al}$ (Ref. 55), Pt (Refs. 22 and 50), and MgO, 51,52 where interactions are decomposed into $\sigma$ and $\pi$ contributions.

\section{CO/Pt QTAIM and orbital approach to hydration and $\mathrm{CO}$ coverage variations}

Here, periodic density functional theory (DFT) ${ }^{53,54}$ is used to model $\mathrm{CO} / \mathrm{Pt}$ with and without hydration at 1/9,1/3, and 5/9 monolayer (ML) $\mathrm{CO}$ coverages. The internal $\mathrm{CO}_{\mathrm{ads}}$ and $\mathrm{C}-\mathrm{Pt}$ bonds are then examined by (1) QTAIM analyses of $\rho(\vec{r})$ and $\nabla^{2} \rho(\vec{r})$ at $\mathrm{C}-\mathrm{O}$ and $\mathrm{C}-\mathrm{Pt}$ bond critical points and (2) $\mathrm{CO}_{\text {ads }}$ orbital approaches. Bond strengths are correlated to changes in the $\left(v_{\mathrm{CO}}\right.$ and $\left.v_{\mathrm{CPt}}\right)$ stretching frequencies, the $\rho(\vec{r}), \nabla^{2} \rho(\vec{r})$, and to QTAIM expressions (vide infra) at critical points vs. CO and water coverages. Changes in the $\rho(\vec{r})$ Hessian non-zero eigenvalues at $\mathrm{C}-\mathrm{O}$ and $\mathrm{C}-\mathrm{Pt}$ bond critical points are directly associated with changes in the $\tilde{\sigma}-$ and $\tilde{\pi}$-systems, which are used by the extended $\pi-\sigma$ model. We also examine the effect of surface relaxation on the above properties by performing frozen and relaxed substrate calculations.

\section{STRUCTURES AND COMPUTATIONAL METHODS}

\section{A. Modelling of the periodic structures}

The Pt substrates were modelled as three-layer fcc (111) periodic slabs with 9 atoms per layer in the unit cell. Figure 2 shows the Pt substrate unit cells, employed in this work, with $\mathrm{CO}_{\text {ads }}$ at $1 / 9$ and 5/9 ML coverages, with and without interacting water molecules. The $\mathrm{C}$ and $\mathrm{O}$ atom Mulliken charges ${ }^{55}$ (Fig. 2) were calculated using relaxed-top substrate layer configurations. The measured Pt lattice parameter of $3.924 \AA$ was used for the calculations performed with (1) all Pt atoms locked at crystallographic lattice positions (frozen substrate calculations), (2) the top substrate layer relaxed, and (3) both the top and the middle layers relaxed (relaxed substrate calculations). In the latter case, 4 of 9 middle layer atoms were constrained to move only perpendicular to the substrate surface to avoid possible alignment of all three layers (i.e., no longer fcc).

At 1/9 and 1/3 ML coverages, the $\mathrm{CO}_{\text {ads }}$ were placed atop as $(3 \times 3)-\mathrm{CO}$ and $(3 \times 3)-3 \mathrm{CO}$ overlayers, respectively, to the fcc lattice and were free to move during geometry optimization. At $1 / 3 \mathrm{ML}$ coverage, the atop $\mathrm{CO}_{\mathrm{ads}}$ were located at the corners of an equilateral triangle. At low coverages, the $\mathrm{CO}$ ads are experimentally observed as atop. ${ }^{56-61}$ The frozen substrate calculations show that the atop is preferred by $\sim 0.04 \mathrm{eV}$ relative to the three-fold site. However, the relaxed substrate calculations show the opposite by $\sim 0.1 \mathrm{eV}$. Feibelman et al., using a variety of DFT codes, found that DFT favors high coordination sites for $\mathrm{CO} / \mathrm{Pt}(111)$ at low $\mathrm{CO}$ coverages, contrary to experiments. This DFT failure is often referred as the "CO adsorption puzzle." 63 In order to reconcile modelling results with experimental observables, the $\mathrm{CO}$ molecules are initially positioned atop for 1/9 ML and 1/3 ML coverages. At 5/9 ML $\mathrm{CO}$ coverage, five $\mathrm{CO}$ are initially placed over the 9 -atom $\mathrm{Pt}$ surface as follows: three atop, one bridge, and one 3-fold site CO.

At 1/9 ML CO coverage, the $\left(\mathrm{CO}+n^{*} \mathrm{H}_{2} \mathrm{O}\right) / \mathrm{Pt}, n \leq 12$ optimized geometries were obtained as follows: For $n=1$, 


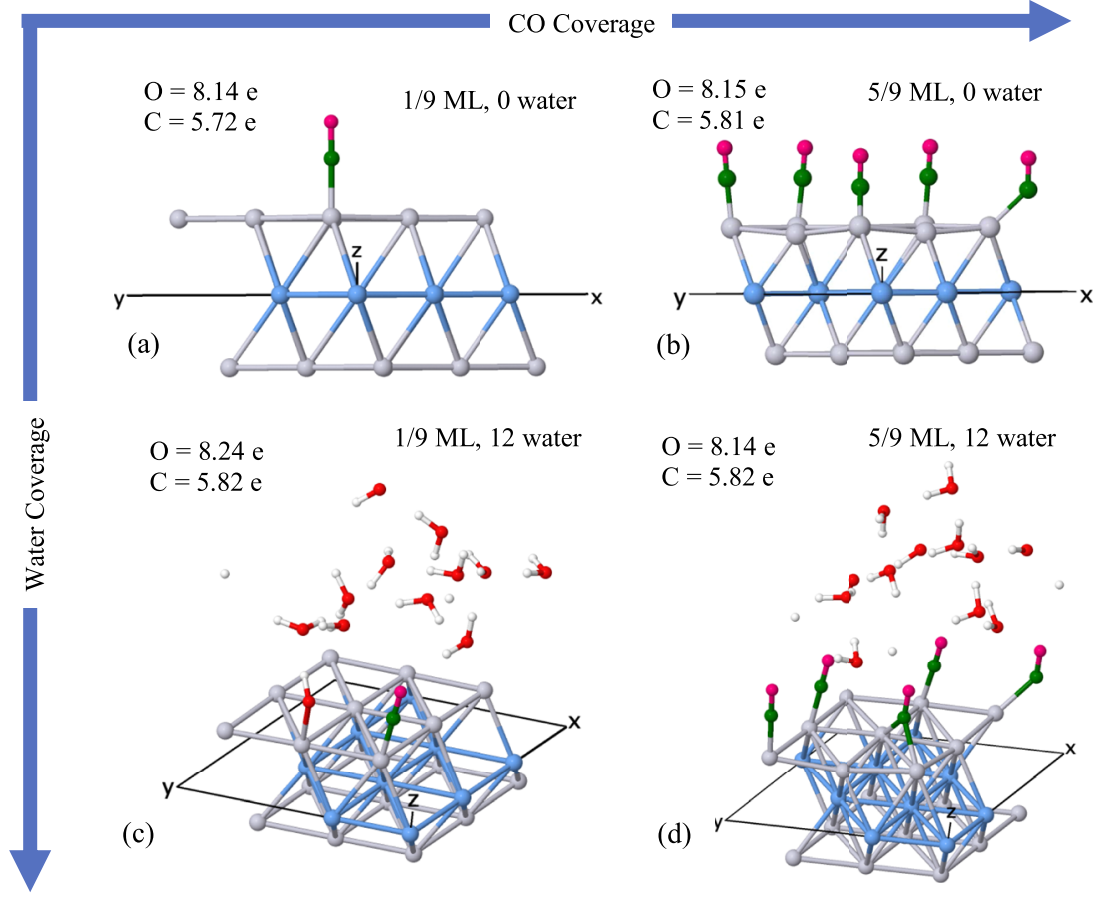

FIG. 2. Unit cells of DFT optimized threelayer Pt slabs with $\mathrm{CO}_{\text {ads }}$, plotted by Jmol, ${ }^{62}$ and $C$ and $O$ Mulliken charges (a) at $1 / 9 \mathrm{ML}$ and (b) $5 / 9 \mathrm{ML} \mathrm{CO}$ coverages on dry $\mathrm{Pt}$, and (c) and (d) are corresponding calculations of (a) and (b), respectively, by including 12 interacting water molecules. Colored atoms are $\mathrm{Pt}$ (top and bottom layers), gray; $\mathrm{Pt}$ (middle layer), light blue; $\mathrm{C}$, green; $\mathrm{O}$ ( $\mathrm{CO}_{\text {ads }}$ ) violet; $\mathrm{O}$ (water), red; and $\mathrm{H}$, white. a single water molecule is placed distantly from a geometry optimized $\mathrm{CO} / \mathrm{Pt}$. This $\left(\mathrm{CO}+\mathrm{H}_{2} \mathrm{O}\right) / \mathrm{Pt}$ initial guess is reoptimized. For $n=2$, a single water molecule is placed distantly from a geometry optimized $\left(\mathrm{CO}+\mathrm{H}_{2} \mathrm{O}\right) / \mathrm{Pt}$, followed by $\left(\mathrm{CO}+2 \mathrm{H}_{2} \mathrm{O}\right) / \mathrm{Pt}$ re-optimization. The process is repeated for all $\left(\mathrm{CO}+n^{*} \mathrm{H}_{2} \mathrm{O}\right) / \mathrm{Pt}, n \leq 12$. Alternate methods to develop the series of geometry optimized solvated structures consistently yielded higher conformation energies than our systematic sequential re-optimization approach, ensuring that our optimized geometries are at a global energy minimum. For the $1 / 3$ and 5/9 ML CO coverages, SCF energy convergence was not possible with a water molecule co-adsorbed on the Pt surface. In these cases, the $\left(\mathrm{CO}+12 * \mathrm{H}_{2} \mathrm{O}\right) / \mathrm{Pt}$ (at the 1/9 ML CO coverage) served as an initial guess followed by separation of the water molecule (co-adsorbed with $\mathrm{CO}$ ) from the Pt surface and its repositioning distant from the remaining water molecules.

At $1 / 9 \mathrm{ML} \mathrm{CO}$, the calculations used optimized geometries of $\left(\mathrm{CO}+n^{*} \mathrm{H}_{2} \mathrm{O}\right) / \mathrm{Pt}, n \leq 12$, at frozen, relaxed top, and relaxed top and second layer Pt. At higher coverages, we used the relaxed $\mathrm{Pt}$ top layer and relaxed top and second layer $\mathrm{Pt}$ for the calculations of $\mathrm{CO} / \mathrm{Pt}$ and $\mathrm{CO}+12^{*} \mathrm{H}_{2} \mathrm{O} / \mathrm{Pt}$.

\section{B. DFT functional, basis sets, and parameters}

Electronic, structural, and vibrational properties of $\mathrm{CO}_{\mathrm{ads}}$ on dry and hydrated Pt were calculated using the CRYSTAL14 DFT code ${ }^{64,65}$ with Gaussian basis sets centered at the atoms. The PBE0 non-empirical/parameter-free functional was used. ${ }^{66,67}$ The $v_{\mathrm{CO}}$ and $v_{\mathrm{CPt}}$ were calculated at the $\Gamma$ point $(\vec{k}=\overrightarrow{0})$ within the harmonic approximation ${ }^{68}$ using a partial Hessian approach for the $\mathrm{CO}_{\text {ads }}$. The innermost Pt orbitals were described by Stuttgart-Dresden effective core potentials (ECP), ${ }^{69,70}$ which accounts for mass-velocity and Darwin relativistic corrections. This provides similar accuracy as the all-electron basis sets, at a fraction of central processing unit (CPU) time. The Pt effective valence basis set [4s4p2d] ${ }^{71}$ was optimized for crystalline calculations. For $\mathrm{C}$ and $\mathrm{O}$, the [4s3p2d] (Ref. 16) basis sets were used, whereas for $\mathrm{H}$, the $[3 \mathrm{~s} 1 \mathrm{p}]^{72}$ basis set was used. The basis sets were size-limited to avoid linear dependencies, resulting from small exponents present in the Gaussian basis sets. Due to the size of the calculations, Brillouin zone integrations were performed on a $6 \times 6$ Monkhorst-Pack grid, ${ }^{73}$ whereas the Fermi energy and the density matrix used the $12 \times 12$ grid (Gilat grid) ${ }^{74,75}$ without loss of accuracy.

Crystal Orbital Overlap Populations $(\mathrm{COOP})^{76}$ were calculated by CRYSTAL14, whereas COOP vs. energy plots were obtained using CRYSTAL17. ${ }^{77}$ SCF energy convergence and geometry optimization parameters were described in our past work (Ref. 17). The $\mathrm{E}_{\mathrm{ads}}$ is given by

$$
\begin{aligned}
\mathrm{E}_{\mathrm{ads}} / \mathrm{n} & =\mathrm{E}_{\left(\mathrm{n} * \mathrm{CO}+\mathrm{m}^{*} \mathrm{H}_{2} \mathrm{O}\right) / \mathrm{Pt}}-\mathrm{E}_{\mathrm{m}} \mathrm{H}_{2} \mathrm{O} / \mathrm{Pt}-\mathrm{n} * \mathrm{E}_{\mathrm{CO}}, \\
\mathrm{n} & =1,2, \ldots, \text { and } \mathrm{m}=0,1,2, \ldots,
\end{aligned}
$$

where $\mathrm{n}$ and $\mathrm{m}$ are the number of $\mathrm{CO}$ and water molecules, respectively. This expression is similar to the one used by Stampfl and Scheffler for $\mathrm{CO}$ and $\mathrm{O}$ co-adsorption on $\mathrm{Ru} .^{78}$ The $E_{a d s}$ is calculated with treatment of the basis set superposition error (BSSE), ${ }^{79}$ which arises due to finite size of the 
crystalline basis sets used. The BSSE error ( $0.1 \mathrm{eV}$, Ref. 17$)$ is minimized using the counterpoise correction ${ }^{80}$ by including "ghost" atoms (i.e., atoms with nuclear charge and electrons removed, but basis set retained) in the fragment SCF energy calculations of the adsorbate-substrate structure.

\section{QTAIM methodology}

The $\rho(\vec{r})$ and $-\nabla^{2} \rho(\vec{r})$ topological analysis was performed with the TOPOND ${ }^{81}$ which is integrated with CRYSTAL14. The bond critical points are denoted as $(3,-1)$, where 3 stands for the three non-zero eigenvalues of the $\rho(\vec{r})$ Hessian at the critical point and -1 is the summation of the number of positive and negative eigenvalues. For the $(3,-1)$ bond critical point, two $\rho(\vec{r})$ curvatures are negative and one is positive, and $\left.\nabla^{2} \rho(\vec{r})\right|_{\vec{r}_{c p}}=\lambda_{1}+\lambda_{2}+\lambda_{3}$, where $\lambda_{\mathrm{i}}(\mathrm{i}=1,2,3)$ are the non-zero eigenvalues of the $\rho(\vec{r})$ Hessian. The $\lambda_{1}$ and $\lambda_{2}$ values $(<0)$ are associated with charge accumulation in the planes perpendicular to the bond path and $\lambda_{3}(>0)$ with charge accumulation along the bond path. Increased $\lambda_{3}$ is indicative of charge accumulation in the atomic basins and the bond being more ionic (Ref. 82).

We also examine a critical point classified as $(3,-3)$, which denotes $\rho(\vec{r})$ local maxima and may correspond to nonnuclear attractors due to $\rho(\vec{r})$ concentration at this point. These points are explored by $-\nabla^{2} \rho(\vec{r})$, which exhibits altering shells of charge concentrations and depletions (valence shell charge concentration-VSCC, Ref. 31). The sign of $\nabla^{2} \rho(\vec{r})$ at the bond critical point can be used to identify the type of the bond and is expected to be negative for covalent and positive for ionic bonds. However, for covalent polar bonds (e.g., $\mathrm{C}-\mathrm{O}$ and $\mathrm{C}-\mathrm{Pt}$ bonds), $\nabla^{2} \rho(\vec{r})$ is positive at the bond critical point (Ref. 37). For covalent bonds, an improved description of the bond strength is given by $(\mathrm{H} / \rho)(\vec{r})$ at the bond critical point $\vec{r}$, such that $H(\vec{r})=G(\vec{r})+V(\vec{r})$, where $G(\vec{r})$ is the positive definite kinetic energy density, and $\mathrm{V}(\vec{r})$ is the potential energy density. ${ }^{36}$ Gatti stated that adoption of a single QTAIM criterion for bond assessment is challenging. ${ }^{83}$ Therefore, we use $\rho(\vec{r}), \nabla^{2} \rho(\vec{r})$, and $(\mathrm{H} / \rho)(\vec{r})$ at $\mathrm{C}-\mathrm{O}$ and $\mathrm{C}-\mathrm{Pt}$ bond critical points to determine changes in the corresponding bond strengths via QTAIM.

\section{COOP and COHP calculations}

For periodic systems, Ruggiero et al. ${ }^{84}$ implemented an improvement to COOP, called Crystal Orbital Hamilton Population (COHP), ${ }^{85}$ and is available in CRYSTAL17. The COHP accurately accounts for bond strengths, by partitioning the band energies (i.e., instead of the electron states) into bonding and antibonding regions. However, both COOP and COHP calculations are basis set dependent. Grechnev et al. ${ }^{86}$ found that COOP and COHP provide acceptable results, when minimal and localized basis sets are used, whereas high-quality basis sets may introduce artificial large antibonding peaks
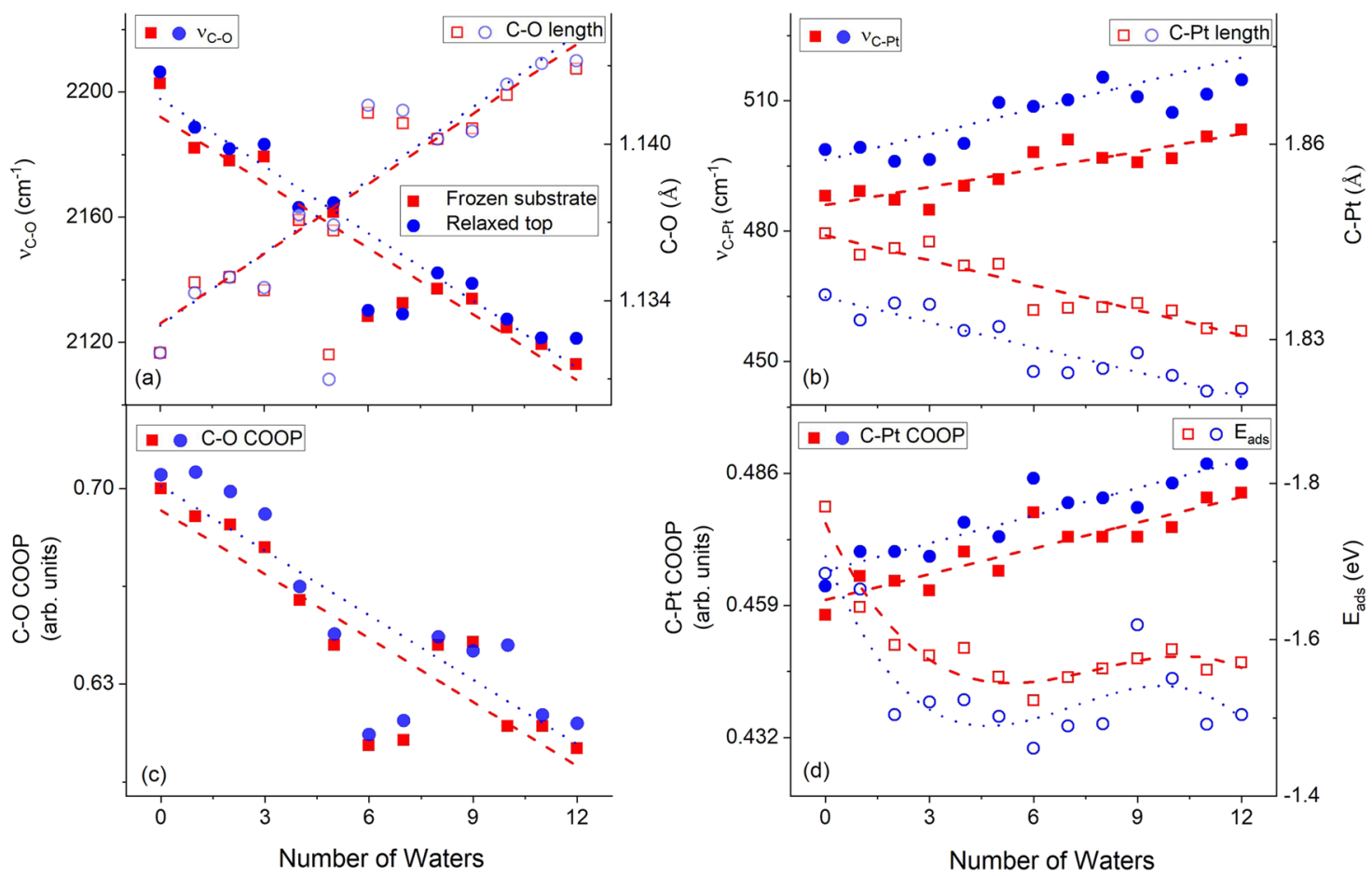

FIG. 3. Frozen (red square) and relaxed top (blue circles) substrate calculations with trend lines (red-dashed and blue-dotted, respectively) for CO/Pt at $1 / 9 \mathrm{ML} C O \mathrm{Coverage}$ vs. water molecule number: (a) $v_{\mathrm{CO}}$ and $\mathrm{C}-\mathrm{O}$ bond lengths, (b) $v_{\mathrm{CPt}}$ and $\mathrm{C}-\mathrm{Pt}$ bond lengths, (c) C-O COOP, and (d) C-Pt COOP and $\mathrm{E}_{\text {ads }}$. 
in the energy region near and below the Fermi level, in both the COOP and COHP spectrums. The C-O COOP and COHP are calculated using the entire basis sets described above, whereas for the $\mathrm{C}-\mathrm{Pt}$ cases, we removed the $\mathrm{s}$ orbital from the carbon outermost sp basis function (outermost carbon $\mathrm{sp}$ basis function is replaced by a $\mathrm{p}$ function) to avoid overestimation of the antibonding $\mathrm{C}-\mathrm{Pt} \mathrm{COOP} / \mathrm{COHP}$ $d_{\tilde{\sigma}}$-band.

\section{RESULTS AND DISCUSSION}

\section{A. Hydration effects for CO/Pt at 1/9 ML CO coverage}

\section{1. $\mathrm{C}-\mathrm{O}$ and $\mathrm{C}-\mathrm{Pt}$ bond lengths, stretching frequencies, COOP, and $E_{\text {ads }}$}

Figure 3 shows the changes in the $\mathrm{C}-\mathrm{O}$ and $\mathrm{C}-$ $\mathrm{Pt}$ bond lengths, the $v_{\mathrm{CO}}, v_{\mathrm{CPt}}$, corresponding COOP, and the $\mathrm{E}_{\mathrm{ads}}$ for $\mathrm{CO} / \mathrm{Pt}$ (frozen and relaxed top substrates) vs. number of waters in the unit cell. Our calculated $v_{\mathrm{CO}}$ values are in the supplementary material (Table SI). At low $(1 / 9 \mathrm{ML}) \mathrm{CO}$ coverage, our $v_{\mathrm{CO}}$ values (dry, 2203 $3_{\text {frozen }}, 2207_{\text {relaxed }} \mathrm{cm}^{-1}$; hydrated with 12 waters: $2113_{\text {frozen }}, 2121_{\text {relaxed }} \mathrm{cm}^{-1}$ ) are $2 \%-6 \%$ higher than that reported by prior computations (dry, 2073-2100 $\mathrm{cm}^{-1}$,
Refs. 59 and 87-90) and experiments (UHV, 2085-2106 $\mathrm{cm}^{-1}$; electrochemical conditions, 2051-2071 $\left.\mathrm{cm}^{-1}\right) .91-93$ Our $v_{\mathrm{CPt}}$ values $\left(488_{\text {frozen }}, 515_{\text {relaxed }} \mathrm{cm}^{-1}\right)$ depend on the number of interacting waters and degree of surface relaxation. Our $v_{\mathrm{CPt}}$ values are close to the value measured under UHV of $480 \mathrm{~cm}^{-1}$ at 0.17 ML CO coverage reported by Steininger et al. (Ref. 59). Our DFT calculations, systematically overestimate $v_{\mathrm{CO}}$ and $\left|\mathrm{E}_{\mathrm{ads}}\right|$ (Ref. 17). Our calculated $\left|E_{\text {ads }}\right|$ for adsorption on dry (1.77$1.68 \mathrm{eV}$ ) and hydrated (1.57-1.50 eV; 12 waters) Pt are within the DFT calculated ranges reported by Steckel et al. ${ }^{94}$ The top layer lifts by $\sim 0.1 \AA$, when allowed to relax. This lattice expansion is accompanied by systematic shifts in $\mathrm{C}-\mathrm{O}$ and $\mathrm{C}-\mathrm{Pt}$ properties (Fig. 3, squares to circles). This top layer relaxation exceeds that reported by Doll (0.05 $\AA$ ) for $\mathrm{CO} / \mathrm{Pt}(111)$ because they used five-layer $\mathrm{Pt}$ (Ref. 71 ). The $\mathrm{C}-\mathrm{O}$ calculated properties [Figs. 3(a) and 3(c), $v_{\mathrm{CO}}, \mathrm{C}-\mathrm{O}$ distance, and $\mathrm{COOP}$ ] are minimally affected upon relaxation of the top layer (blue circles) compared to that of the frozen substrate (red squares).

The negative correlation between bond lengths and stretching frequencies is known as Badger's rule. ${ }^{95-97} \mathrm{We}$ found Badger's rule applicable to the internal $\mathrm{CO}_{\mathrm{ads}}$ and $\mathrm{C}-\mathrm{Pt}$ bonds at low CO coverage, where the $\mathrm{C}-\mathrm{O}$ bond weakens with
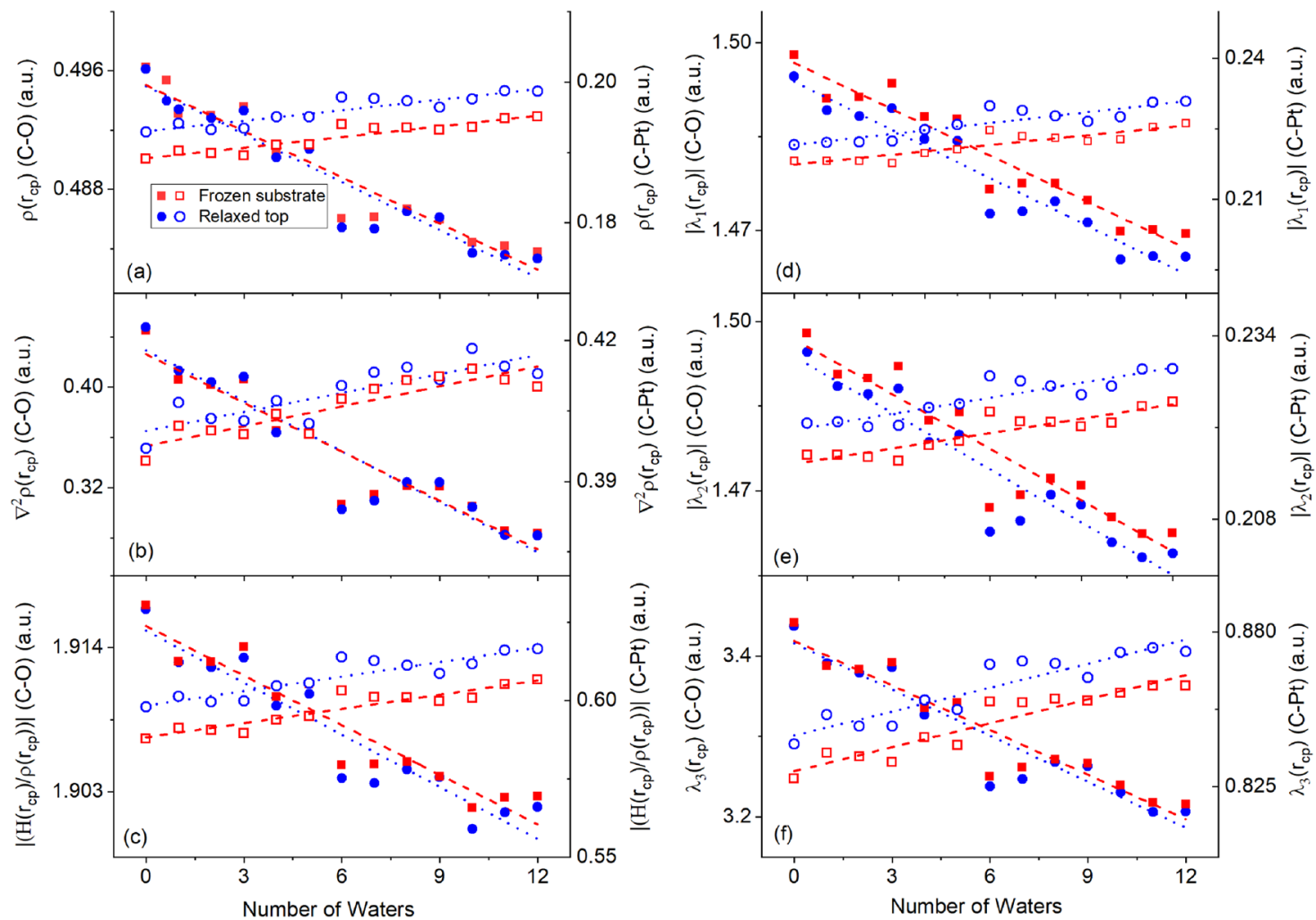

FIG. 4. Frozen (red squares) and relaxed top (blue circles) Pt substrate calculations with trend lines (red-dashed and blue-dotted, respectively) for C-O (solid) and C-Pt (open), (a) $\rho(\vec{r})$, (b) $\nabla^{2} \rho(\vec{r}),($ c $) H / \rho(\vec{r})$, and (d) $-(\mathrm{f}) \rho(\vec{r})$ Hessian of the non-zero eigenvalues $\lambda_{\mathrm{i}}(\mathrm{i}=1,2,3)$ at the $\mathrm{C}-\mathrm{O}$ and $\mathrm{C}-\mathrm{Pt}$ bond critical points relative to the number of interacting water molecules for CO/Pt at $1 / 9 \mathrm{ML}$ CO coverage. 
hydration. This is confirmed by the $v_{\mathrm{CO}}$ downshift [Fig. 3(a), solid], the increase in the $\mathrm{C}-\mathrm{O}$ bond lengths [Fig. 3(a), hollow], and the decrease in the $\mathrm{C}-\mathrm{O}$ COOP [Fig. 3(c)]. The $v_{\mathrm{CO}}$ downshift with hydration is in agreement with infrared reflection absorption spectroscopy (Ref. 92).

At low CO coverage, $\mathrm{C}-\mathrm{Pt}$ bond strengthening with hydration is verified by the $v_{\mathrm{CPt}}$ upshift [Fig. $3(\mathrm{~b})$, solid], the decrease in the $\mathrm{C}-\mathrm{Pt}$ bond lengths [Fig. 3(b), hollow], and the increase in the C-Pt COOP [Fig. 3(d)]. While this does not appear to be consistent with corresponding changes in the $\mathrm{E}_{\mathrm{ads}}$ [Fig. 3(d)], the absence of correlation between the Cmetal stretching frequency and the corresponding $\mathrm{E}_{\mathrm{ads}}$ has been reported (Refs. 14, 17, and 88). The C-metal stretching frequency and $\mathrm{E}_{\mathrm{ads}}$ are derived from local and global properties of the potential energy surface, respectively: The $\mathrm{C}$-metal stretching frequency is more closely associated with localized interactions of the adsorbate with the metal atom, whereas the $E_{\text {ads }}$ is associated with interactions between the adsorbate and the entire substrate surface. The lack of $v_{\mathrm{CPt}}$ and $E_{a d s}$ correlation is attributed to direct charge transfer from water molecules to $\mathrm{CO}_{\mathrm{ads}}$. Specifically, for $\mathrm{CO}_{\mathrm{ads}}$ on hydrated $\mathrm{Pt}$ (12 waters), the $\mathrm{CO}_{\mathrm{ads}}$ charge is increased by $\sim 0.19 e$ [Figs. 2(a) and 2(c)] due to decreases in charges of the adsorbing $\mathrm{Pt}(0.13 e)$ and surrounding water molecules (0.06e).

At low CO coverage, one water molecule is co-adsorbed with $\mathrm{CO}$ on the Pt surface [Fig. 2(c)], whereas this effect is not observed at higher $\mathrm{CO}$ coverages [Fig. 2(d)]. As hydration is increased [Figs. 2(a)-2(c)], electrons are transferred from the water molecules to both the $\mathrm{C}$ and $\mathrm{O}$ atoms (Fig. 2, Mulliken charges): Thus, the $\mathrm{CO}$ contribution to the occupied $2 \tilde{\pi}^{*}$-band increases and leads to $\mathrm{C}-\mathrm{O}$ bond weakening
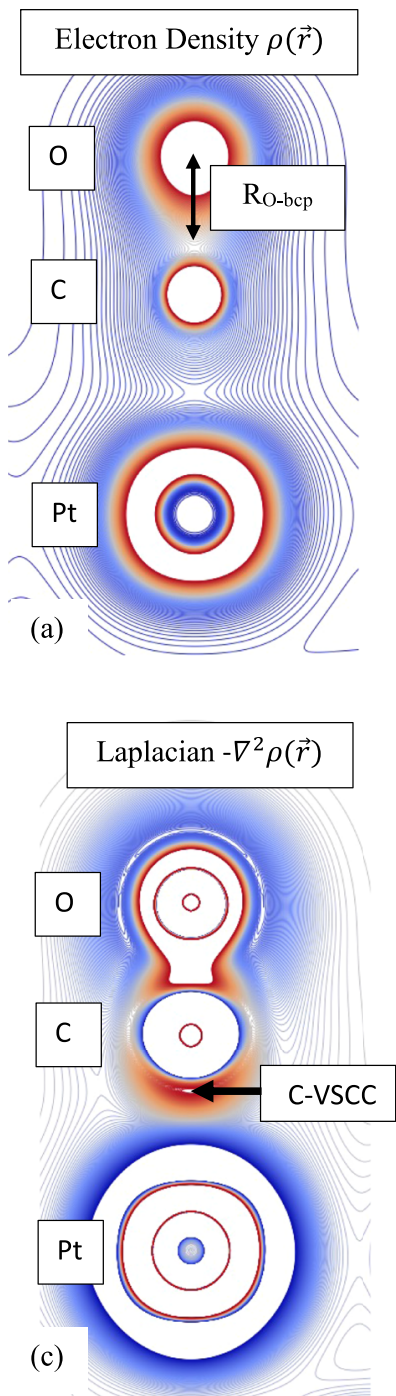
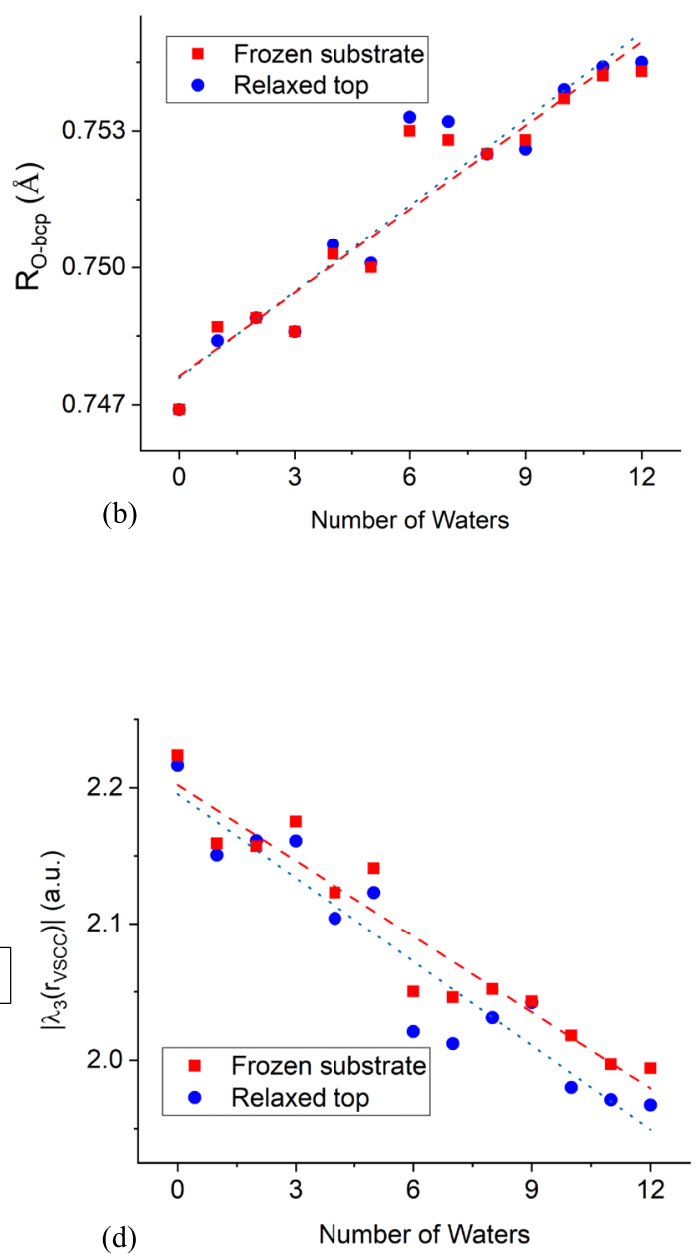

FIG. 5. QTAIM calculated properties for $\mathrm{CO}_{\text {ads }}$ on Pt at $1 / 9 \mathrm{ML}$ CO coverage at varied hydration: (a) extrema electron density $\rho(\vec{r})$ (dry case: high charge, red; low charge, blue), (b) distance from oxygen to the $\mathrm{C}-\mathrm{O}$ bond critical point $\left(R_{0-b c p}\right)$ vs waters number, $(c)$ extrema Laplacian $-\nabla^{2} \rho(\vec{r})$ (dry case: high charge, red; low charge, blue), and (d) carbon non-bonding valence shell charge concentration [VSCC, $(3,-3)$ ] $\left|\lambda_{3}\right|$ value vs. waters number. 
and $\mathrm{C}-\mathrm{Pt}$ bond strengthening. At higher $\mathrm{CO}$ coverages, deviations from the rule are noticed. Similarly, the observed positive correlation between the COOP and stretching frequencies at low $\mathrm{CO}$ coverage is not observed at higher coverages (vide infra).

\section{2. $C-O$ and $C-P t$ bond strengths by QTAIM}

Figure 4 shows the values of $\rho(\vec{r}), \nabla^{2} \rho(\vec{r})$, and $|H / \rho(\vec{r})|$ at the $\mathrm{C}-\mathrm{O}$ and $\mathrm{C}-\mathrm{Pt}$ bond critical points vs. number of interacting waters and the $\rho(\vec{r})$ Hessian $\lambda_{\mathrm{i}}$ eigenvalues $(\mathrm{i}=1,2,3)$ at the $\mathrm{C}-\mathrm{O}$ and $\mathrm{C}-\mathrm{Pt}$ bond critical points. The decrease in $\rho(\vec{r}), \nabla^{2} \rho(\vec{r})$, and $|\mathrm{H} / \rho(\vec{r})|$ at the $\mathrm{C}-\mathrm{O}$ bond critical point [Figs. 4(a)-4(c), solid], as hydration increases, is indicative of internal $\mathrm{CO}_{\mathrm{ads}}$ bond weakening. The opposite is observed at the $\mathrm{C}-\mathrm{Pt}$ bond critical point [Figs. 4(a)-4(c), hollow]. This agrees with changes from the $v_{\mathrm{CO}}$ and $v_{\mathrm{CPt}}$, the corresponding bond lengths, and the COOP (Fig. 3). The $\rho(\vec{r}), \nabla^{2} \rho(\vec{r})$, and $|H / \rho(\vec{r})|$ at bond critical points [Figs. 4(a)-4(c)] are negatively correlated to changes in the corresponding bond lengths [Figs. 3(a) and 3(b), hollow] throughout this work. The above QTAIM properties at bond critical points have a positive correlation with corresponding stretching frequencies for all cases except $\mathrm{CO}_{\mathrm{ads}}$ on dry Pt at CO coverages $>1 / 9 \mathrm{ML}$. This will be reconciled in Sec. III B 2.

Upon hydration, the $\left|\lambda_{\mathrm{i}}\right|$ eigenvalues [Figs. 4(d)-4(f)] at the $\mathrm{C}-\mathrm{O}$ bond critical point (solid) decrease, while those of the $\mathrm{C}-\mathrm{Pt}$ bond critical point (hollow) increase. This negative correlation was found for all co-adsorption scenarios involving atop $\mathrm{CO}_{\mathrm{ads}}$. The $\left|\lambda_{\mathrm{i}}\right|$ eigenvalues positive correlations to the $\rho(\vec{r}), \nabla^{2} \rho(\vec{r})$, and $|\mathrm{H} / \rho(\vec{r})|$ at the C-O and C-Pt bond critical points are observed for all adsorptions and coverages. We confirm a positive correlation of $\left|\lambda_{1}\right|$ and $\left|\lambda_{2}\right|$ eigenvalues to $\mathrm{C}-\mathrm{O} \pi$ bonding and the same for $\lambda_{3}$ values to $\mathrm{C}-\mathrm{O} \sigma$ bonding (vide infra).

Figure 5 shows the oxygen to $\mathrm{C}-\mathrm{O}$-bond-critical-point distance $\left(\mathrm{R}_{\mathrm{O}-\mathrm{bcp}}\right)$ from the $\rho(\vec{r})$ [Figs. 5(a) and 5(b)] and the carbon $(3,-3)$ non-bonding VSCC $-\nabla^{2} \rho(\vec{r})\left|\lambda_{3}\right|$ eigenvalue [Figs. 5(c) and 5(d)] vs. water number for $1 / 9 \mathrm{ML} \mathrm{CO}_{\mathrm{ads}}$ on Pt. The increase of $\mathrm{R}_{\mathrm{O}-\mathrm{bcp}}$ with hydration [Fig. $5(\mathrm{~b})$ ] is consistent with internal $\mathrm{CO}_{a d s}$ bond weakening and increased $\mathrm{CO}$ contribution to the $\mathrm{C}-\mathrm{O}$ antibonding $2 \tilde{\pi}^{*}$-band (Ref. 37$)$. The $(3,-3)$ carbon VSCC $\left|\lambda_{3}\right|$ eigenvalue [Fig. 5(d)] decreases with hydration, suggesting a decrease in the carbon non-bonding $\rho(\vec{r})$ along the $\mathrm{C}-\mathrm{Pt}$ axis. The $\mathrm{C}-\mathrm{Pt}$ bond critical point $\lambda_{3}$ eigenvalue
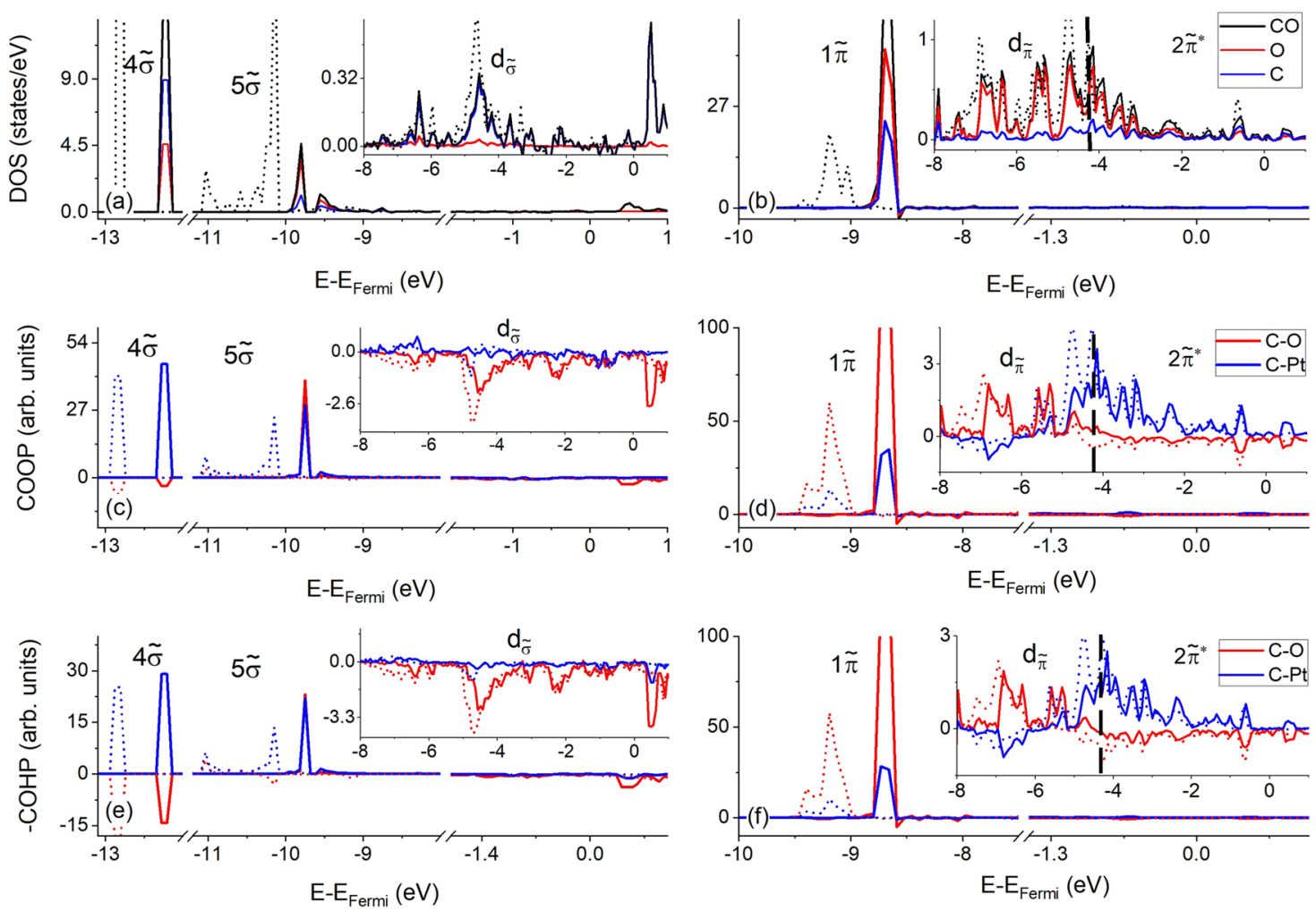

FIG. 6. DFT calculated spectra of $\mathrm{CO}_{\mathrm{ads}}$ on dry (solid) and hydrated (dotted; 12 waters) Pt at $1 / 9 \mathrm{ML}$ CO coverage with a relaxed top Pt substrate layer: (a) and (b), DOS (black, CO; red, O; blue, C), (c) and (d), COOP (red, C-O; blue, C-Pt), and (e) and (f) -COHP (red, C-O; blue, C-Pt). Vertical dashed black lines, $d_{\tilde{\pi}}{ }^{-}$and $2 \tilde{\pi}^{*}$-energy bands region separation. 
increases [Fig. 4(f)] with hydration, suggesting that the $\mathrm{C}-\mathrm{Pt}$ $\tilde{\sigma}$-system becomes more ionic (i.e., charge is concentrated in the $\mathrm{C}$ and $\mathrm{Pt}$ basins).

\section{C-O and C-Pt overlap populations and phenomenological models}

The relationship between internal $\mathrm{CO}_{\mathrm{ads}}$ and $\mathrm{C}-\mathrm{Pt}$ bond strengths to surface hydration were correlated to $\mathrm{C}-\mathrm{O}$ and $\mathrm{C}-\mathrm{Pt}$ overlap populations. Moreover, these changes in bond strengths are predicted by the $5 \sigma$ donation $-2 \pi^{*}$ backdonation and extended $\pi-\sigma$ models. Figure 6 shows the DOS, COOP, and -COHP spectra at $1 / 9$ ML CO coverage with the top Pt layer relaxed, with and without 12 interacting water molecules. Positive and negative COOP denote bonding and antibonding (i.e., extent of bonding), respectively. The -COHP is equivalent to COOP, thus COOP and -COHP predict extent of bonding (i.e., COOP gives bond order; -COHP gives bond strength, Ref. 77).

The COOP and -COHP [Figs. 6(c)-6(f)] confirm the C-O and $\mathrm{C}-\mathrm{Pt}$ extent of bonding in terms of the $\tilde{\sigma}-$ and $\tilde{\pi}-$ systems orbitals/bands, described in the introduction. Hydration shifts the $4 \tilde{\sigma}$ and $5 \tilde{\sigma}$ orbitals towards more negative energies and broadens the $5 \tilde{\sigma}$ orbital as seen by the DOS, COOP, and COHP spectra [Figs. 6(a), 6(c), and 6(e)]. For dry [Fig. 6(e), solid red] and hydrated [Fig. 6(e), dotted red, 12 waters]
$\mathrm{CO} / \mathrm{Pt}$, the $5 \tilde{\sigma} \mathrm{C}-\mathrm{O}$ strengths, given by -COHP, are about $40 \%$ (dry) and $10 \%$ (hydrated) of comparable $4 \tilde{\sigma}$ strengths: The -COHP (and COOP) spectra integrations show that hydration enhances the $4 \tilde{\sigma} \mathrm{C}-\mathrm{O}$ antibonding character and diminishes the $5 \tilde{\sigma} \mathrm{C}-\mathrm{O}$ bonding character. Moreover, the COOP and -COHP show that changes in the $d_{\tilde{\sigma}}$-band upon hydration further weaken the internal $\mathrm{CO}_{\text {ads }}$ bond [Figs. 6(c) and 6(e) insets, solid and dotted red lines]. The DOS shows that the $4 \tilde{\sigma}$ orbital is polarized towards carbon, whereas the $5 \tilde{\sigma}$ orbital is polarized towards oxygen [Fig. 6(a), blue and red solid lines]. These polarizations are opposite to those of the free $\mathrm{CO} 4 \sigma$ and $5 \sigma$ molecular orbitals, in agreement with past reports (Refs. 10-14, 17 , and 15).

Hydration downshifts and broadens all $\tilde{\pi}$-system orbital/bands [Figs. 6(b), 6(d), and 6(f)]. This decreases the $\mathrm{C}-\mathrm{O} 1 \tilde{\pi}$ orbital bonding and substantially increases the $2 \tilde{\pi}^{*}$ antibonding, whereas the $d_{\tilde{\pi}}$-band remains relatively unchanged [Fig. 6(f), solid and dotted red lines integrations], which is in agreement with changes in the orbitals/bands $\mathrm{CO}$ contributions, as shown by DOS integrations. The DOS, COOP, and -COHP show that the $\tilde{\sigma}$ - and $\tilde{\pi}$-systems weaken the internal $\mathrm{CO}_{\mathrm{ads}}$ bond upon hydration. The COOP and the -COHP spectra facilitate the selection of the $d_{\tilde{\pi}^{-}}$and $2 \tilde{\pi}^{*}-$ bands energy regions for calculation of corresponding $\mathrm{CO}$ contributions used in phenomenological models.
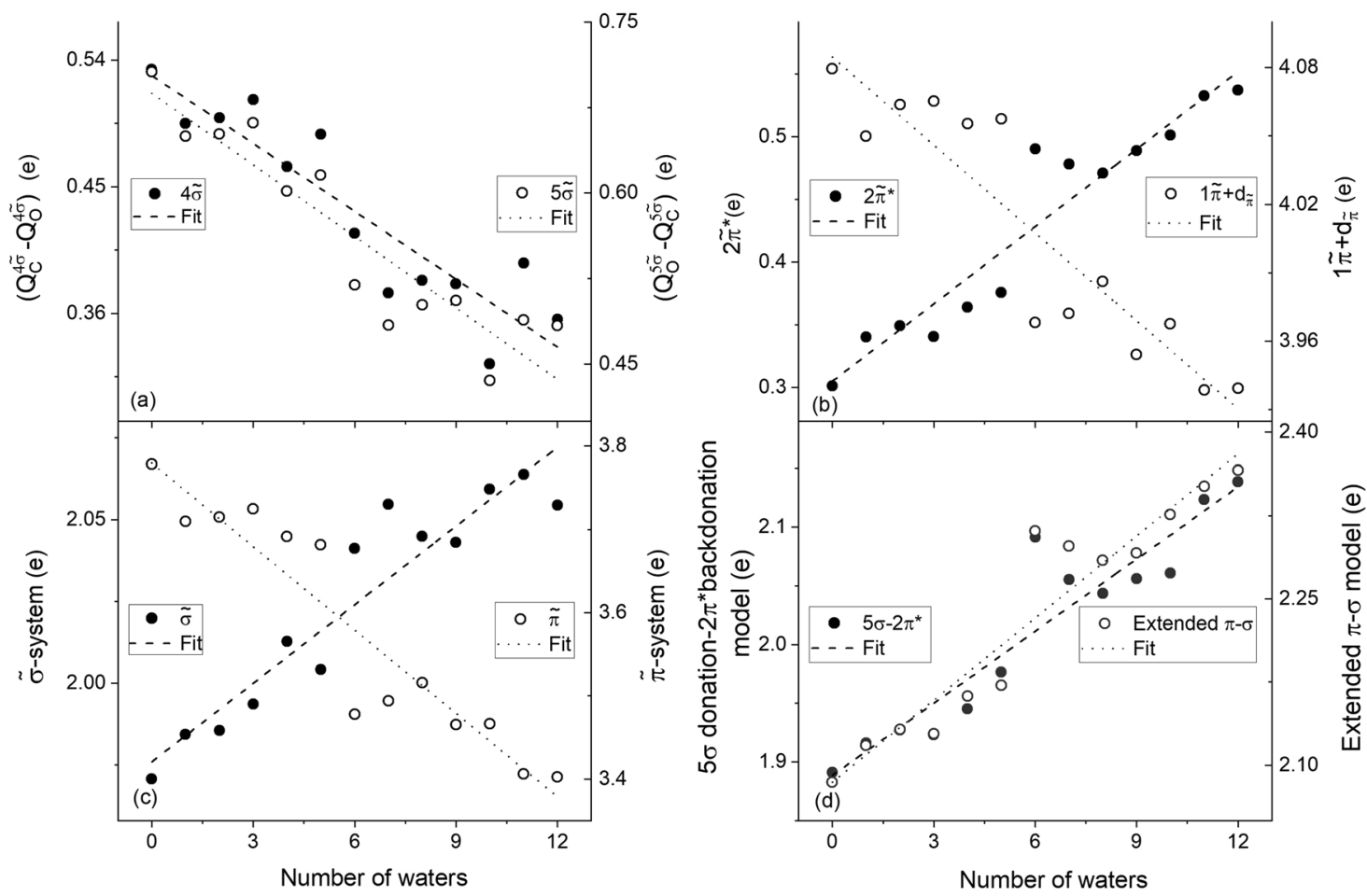

FIG. 7. (a) Charge differences between $\mathrm{C}$ and $\mathrm{O}$ for the $\mathrm{CO} / \mathrm{Pt}$ at $1 / 9 \mathrm{ML} \mathrm{CO}$ coverage, calculated by relaxing the Pt substrate top layer relative to the number of interacting water molecules for $4 \tilde{\sigma}$ and $5 \tilde{\sigma}$ orbitals. The $\mathrm{CO}$ contributions to the (b) $1 \tilde{\pi}$ and $d_{\tilde{\pi}}$-band and the $2 \tilde{\pi}^{*}$-band and (c) the $\tilde{\sigma}$-and $\tilde{\pi}$-systems. Outputs from (d) $5 \sigma$ donation- $2 \pi^{*}$ backdonation model and the $\pi-\sigma$ model [Eq. (1)]. The CO contributions to the $\tilde{\sigma}$-system do not include the $5 \tilde{\sigma}$ orbital. 
Figure 7 shows charge differences between $\mathrm{C}$ and $\mathrm{O}$ for the $4 \tilde{\sigma}$ and $5 \tilde{\sigma}$ orbitals, the CO contributions to the $1 \tilde{\pi}+d_{\tilde{\pi}}$, the $2 \tilde{\pi}^{*}$-band, and the $\tilde{\sigma}$ - and $\tilde{\pi}$-systems, as well as the $5 \sigma$ donation $-2 \pi^{*}$ backdonation model and the extended $\pi-\sigma$ model [Eq. (1)] relative to the number of interacting waters (relaxed top substrate calculations). Hydration decreases both the $4 \tilde{\sigma}$ and $5 \tilde{\sigma}$ polarizations towards carbon and the oxygen, respectively [Fig. 7(a)], and increases the $\mathrm{CO}$ contributions to the $\tilde{\sigma}$-system [Fig. 7(c), solid circle and Fig. S1]. These effects weaken the internal $\mathrm{CO}_{\text {ads }}$ and $\mathrm{C}-\mathrm{Pt}$ bonds.

The overall decreased $\mathrm{CO}$ contribution to the $\tilde{\pi}$-system upon hydration, weakens the internal $\mathrm{CO}_{\mathrm{ads}}$ bond [Fig. $7(\mathrm{~b})$, hollow circles]. This is attributed to increased $\mathrm{CO}$ charges in the $\mathrm{C}-\mathrm{O}$ antibonding $2 \tilde{\pi}^{*}$-band [Fig. $7(\mathrm{~b})$, solid circles] and decreases in the net $\mathrm{CO}$ contribution to the $1 \tilde{\pi}$ orbital and the $d_{\tilde{\pi}}$-band, both being $\mathrm{C}-\mathrm{O}$ bonding [Fig. $7(\mathrm{~b})$, hollow circles]. The overall strengthening of the $\mathrm{C}-\mathrm{Pt}$ bond is due to a competition between the $\mathrm{C}-\mathrm{Pt} \tilde{\sigma}-$ and the $\tilde{\pi}$-systems.
More specifically, hydration enhances $\mathrm{C}-\mathrm{Pt}$ antibonding, via changes in the $\tilde{\sigma}$-system, and increases $\mathrm{C}$-Pt bonding, via changes in the $\tilde{\pi}$-system. Both phenomenological models predict weakening of the internal $\mathrm{CO}_{\mathrm{ads}}$ bond, along with increased hydration [Fig. 7(d)]. However, the agreement of the $5 \sigma$ donation $-2 \pi^{*}$ backdonation model in the weakening of the internal $\mathrm{CO}_{\text {ads }}$ bond is fortuitous. The $5 \sigma$ donation- $2 \pi^{*}$ backdonation model uses the free $\mathrm{CO} 5 \sigma$ and $2 \pi^{*}$ molecular orbitals charges ( $\mathrm{C}-\mathrm{O}$ antibonding) to estimate the internal $\mathrm{CO}_{\text {ads }}$ bond strength. At low $\mathrm{CO}$ coverage, the 5o charge is constant upon hydration, and thus the weakening of the internal $\mathrm{CO}_{\mathrm{ads}}$ bond is only due to increases in the $2 \pi^{*}$ charge (i.e., single parameter model).

\section{QTAIM and orbital analyses comparison}

For $\mathrm{CO}_{\text {atop }}$ at $1 / 9$ ML coverage, QTAIM and phenomenological models show that the internal $\mathrm{C}-\mathrm{O}$ bond weakens, while the $\mathrm{C}-\mathrm{Pt}$ bonds strengthens (via competition between
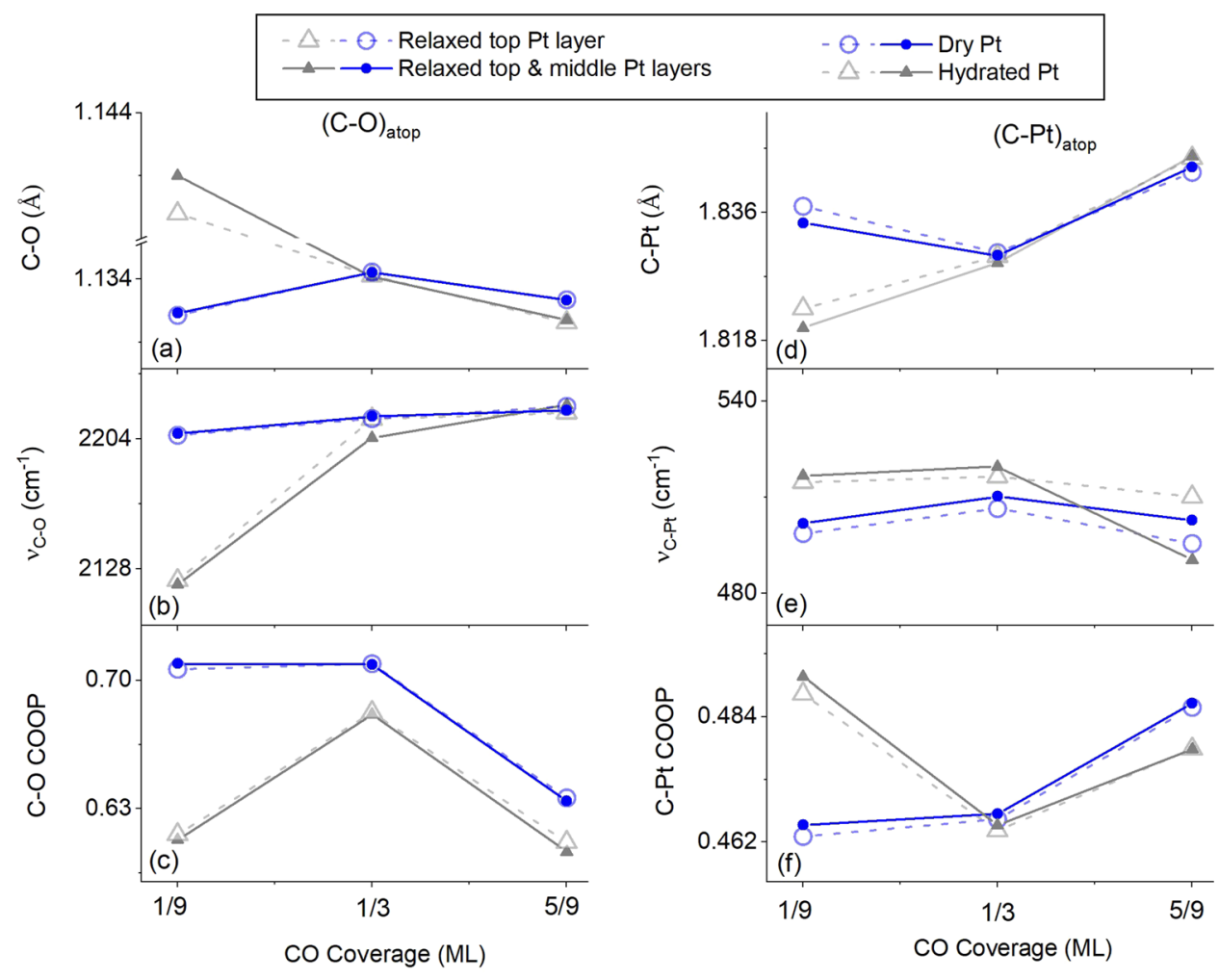

FIG. 8. DFT calculated properties vs $\mathrm{CO}$ atop coverage on dry (blue circles) and hydrated (gray triangles, 12 water) Pt. Relaxed top substrate layer (hollow shapes); Both top and middle substrate layers relaxed (solid shapes): (a) $\mathrm{C}-\mathrm{O}$ bond length, (b) $v_{\mathrm{CO}}$, (c) $\mathrm{C}-\mathrm{O}$ COOP (d) C-Pt bond length, (e) $v_{\mathrm{CPt}}$, (f) $\mathrm{C}-\mathrm{Pt}$ COOP, and (g) C-Pt COOP and $\mathrm{E}_{\text {ads }}$

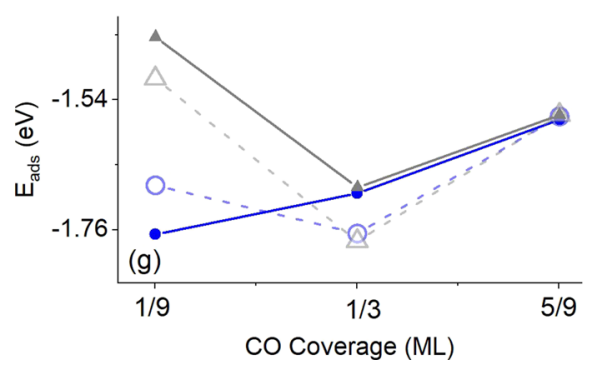


$\tilde{\sigma}$ - and system $\tilde{\pi}$-systems) with hydration. The decreased C-O critical point $\left|\lambda_{1}\right|$ and $\left|\lambda_{2}\right|$ eigenvalues [Figs. 4(d) and 4(e)] and increases in $\mathrm{R}_{\mathrm{O}-\mathrm{bcp}}$ values [Fig. 5(b)] correspond to weaker $\mathrm{C}-\mathrm{O} \pi$ bonding. Moreover, the decreased $\lambda_{3}$ eigenvalue at the C-O critical point [Fig. 4(f)] corresponds to a weaker C-O $\sigma$ bonding.

\section{B. CO coverage effect for adsorption on dry and hydrated $\mathrm{Pt}$}

\section{1. $\mathrm{C}-\mathrm{O}$ and $\mathrm{C}-\mathrm{Pt}$ stretching frequency and bond length coverage dependence}

We quantified effects of CO coverage and hydration on atop internal $\mathrm{C}-\mathrm{O}$ and $\mathrm{C}-\mathrm{Pt}$ bond strengths by QTAIM and adsorbate orbital analyses as described above. Figure 8 shows the variation of $v_{\mathrm{CO}}$ and $v_{\mathrm{CPt}}$, bond lengths, COOP, and the $\mathrm{E}_{\mathrm{ads}}$ (on dry and hydrated $\mathrm{Pt}$ ) with coverage at $1 / 9 \mathrm{ML}, 1 / 3 \mathrm{ML}$, and $5 / 9 \mathrm{ML}$. The $v_{\mathrm{CO}}$ upshift with coverage, has been attributed to decreased $2 \pi^{*}$-backdonation. ${ }^{98}$ Liu et al. explained further that at higher coverages, competition for a finite number of $\mathrm{d}$-band electrons results in a per molecule reduction of $2 \pi^{*}-$ backdonation (Ref. 91). The $v_{\mathrm{CO}}$ upshift is also a consequence of dipole-dipole (i.e., intermolecular) coupling (Refs. 20 and 98-101). Thus, CO intermolecular coupling serves as a probe for CO island formation (Refs. 92, 102, and 103). Our $v_{\mathrm{CO}}$ values are upshifted along with the increased CO coverage by about $13 \mathrm{~cm}^{-1}$ and $97 \mathrm{~cm}^{-1}$, for adsorption on dry and hydrated
Pt, respectively [Fig. 8(b)]. In the latter case, the substantial $v_{\mathrm{CO}}$ upshift is mostly between the $\mathrm{CO} / \mathrm{Pt}$ configurations at $1 / 9 \mathrm{ML}$ and 1/3 ML CO coverages and is attributed to the water-CO co-adsorption that appears at the low $\mathrm{CO}$ coverage but is absent at higher coverages [Fig. 2(c)]. Moreover, these $v_{\mathrm{CO}}$ upshifts are accompanied by decreases in the $\mathrm{C}-\mathrm{O}$ bond lengths [Fig. 8(a)], in agreement with Badger's rule (i.e., negative correlation between bond lengths and stretching frequencies, Refs. 95-97).

In the absence of hydration, the correlations between changes in the $\mathrm{C}-\mathrm{O}$ distances and $v_{\mathrm{CO}}$, as the $\mathrm{CO}$ coverage varies [Figs. 8(a) and 8(b)], do not adhere to Badger's rule (i.e., not negatively correlated). For these cases, the internal $\mathrm{CO}_{\text {ads }}$ bond strength, predicted by the QTAIM properties $\rho(\vec{r})$, $\nabla^{2} \rho(\vec{r})$, and $|\mathrm{H} / \rho(\vec{r})|$ at the $\mathrm{C}-\mathrm{O}$ bond critical point, is near constant between 1/9 ML and 5/9 ML CO coverages, in contrast with $v_{\mathrm{CO}}$ upshifting (vide infra). The $v_{\mathrm{CO}}$ upshift with increasing CO coverage, Fig. 8(b), is consistent with past reports for adsorption on hydrated (Ref. 91) and dry Pt (Refs. 16, 89, 90, 94 and 104-106) and is consistent with internal $\mathrm{CO}_{\mathrm{ads}}$ bond strengthening.

Similar to our past report for $\mathrm{CO}_{\mathrm{ads}}$ on Pt and $\mathrm{Ru}$ surfaces, at high $\mathrm{CO}$ coverages, changes in the $\mathrm{C}-\mathrm{O}$ and $\mathrm{C}-\mathrm{Pt}$ COOP [Figs. 8(c) and 8(f)] do not correlate with changes in the $v_{\mathrm{CO}}$ and $v_{\mathrm{CPt}}$ [Figs. 8(b) and 8(e)], respectively (Ref. 16). Negative correlations between COOP and corresponding stretching frequencies for adsorption on dry Pt have been attributed
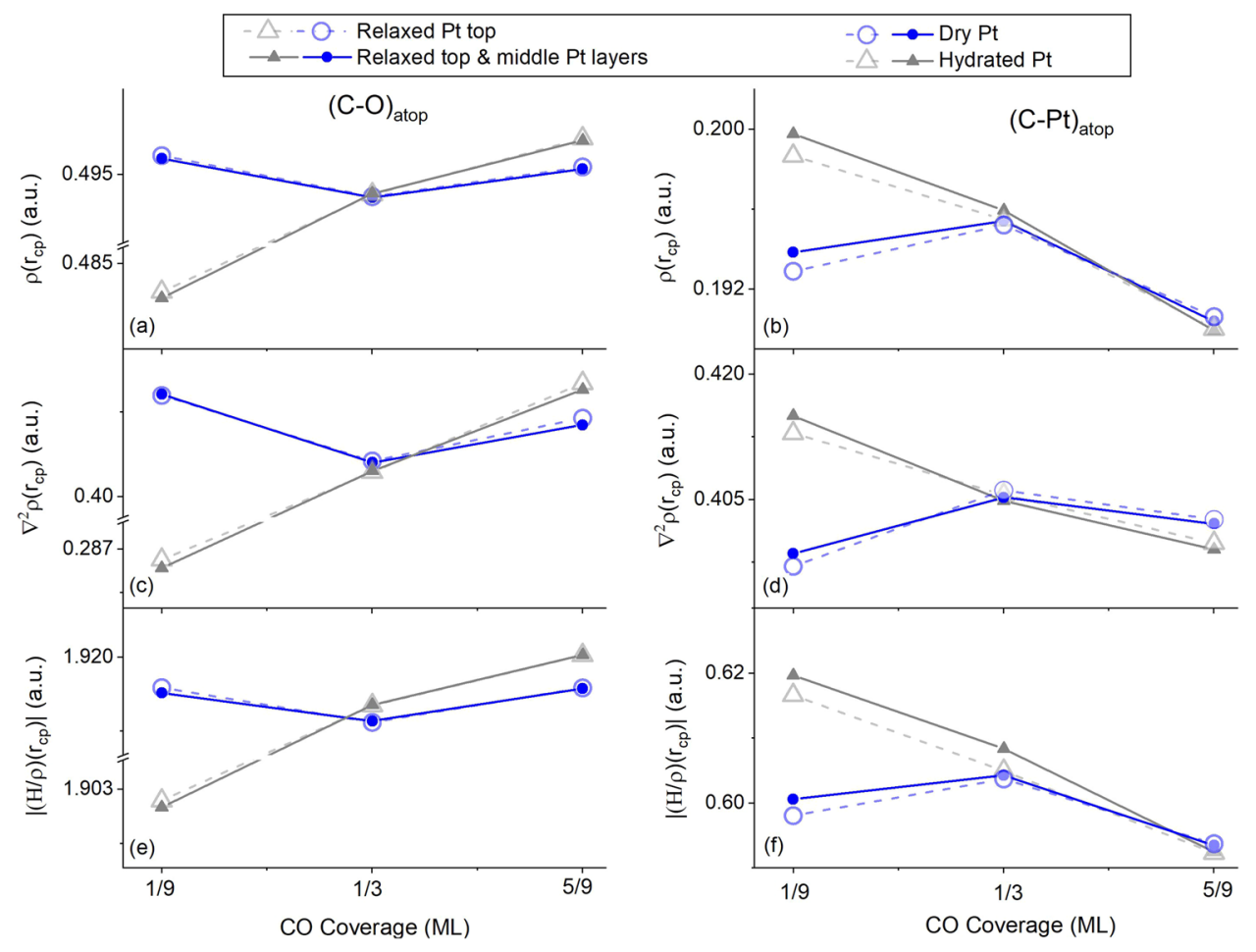

FIG. 9. QTAIM calculated properties at the $\mathrm{C}-\mathrm{O}$ and $\mathrm{C}-\mathrm{Pt}$ bond critical points vs. $\mathrm{CO}$ atop coverage on dry (blue circles) and hydrated (gray triangles, 12 water) Pt. Relaxed top substrate (hollow shapes); Both top and middle substrate layers relaxed (solid shapes): (a) and (b) $\rho(\vec{r})$, (c) and (d) $\nabla^{2} \rho(\vec{r})$, and (e) and (f) $\mathrm{H} / \rho(\vec{r})$ 
to hybridization defects (Ref. 17). Kaupp et al. reported that shorter bonds are not necessarily stronger bonds, due to possible sp hybridization defects, where the s orbital may have insufficient charge to hybridize with the p orbital. ${ }^{107}$ Increased CO coverage, from 1/9 ML to 5/9 ML, weakens the $\mathrm{C}-\mathrm{Pt}$ bond, as verified by the downshifts of the $v_{\mathrm{CPt}}$ [averaged between the two relaxed substrate calculations, Fig. 8(e)] and the increases in the C-Pt distances [Fig. 8(d)]. The weakening of the $\mathrm{C}-\mathrm{Pt}$ bond with increased $\mathrm{CO}$ coverage is more pronounced with hydration. Concomitantly, for adsorption on dry $\mathrm{Pt}$, the $\mathrm{E}_{\mathrm{ads}}$ becomes less negative, which is in agreement with past reports [Fig. 8(f), blue lines and symbols and Ref. 16]. Whereas, when water is present, the 1/9 ML and 5/9 ML CO coverage $\mathrm{E}_{\mathrm{ads}}$ are about the same and are significantly more negative at the $1 / 3 \mathrm{ML}$ coverage [Fig. 8(f), gray lines and symbols]. As in Sec. III A, there is no general trend between the $v_{\mathrm{CPt}}$ and $\mathrm{E}_{\mathrm{ads}}$, and this is also found in Sec. III C.

\section{QTAIM and phenomenological models}

Figure 9 shows the QTAIM properties $\rho(\vec{r}), \nabla^{2} \rho(\vec{r})$, and $|\mathrm{H} / \rho(\vec{r})|$ at the $\mathrm{C}-\mathrm{O}$ and $\mathrm{C}-\mathrm{Pt}$ bond critical points, at various CO coverages for atop adsorption on dry and hydrated Pt. Corresponding changes in the $\left|\lambda_{i}\right|(i=1,2,3)$ eigenvalues are shown in Fig. S2 and they follow the same pattern as Fig. 8 QTAIM properties. The values of these properties at the $\mathrm{C}-\mathrm{O}$ and $\mathrm{C}-\mathrm{Pt}$ bond critical points reveal some noteworthy differences for the strength of the corresponding bonds between adsorption on dry and hydrated $\mathrm{Pt}$, as $\mathrm{CO}$ coverage increases. More specifically, for adsorption on dry Pt, the predicted QTAIM internal $\mathrm{CO}_{\mathrm{ads}}$ bond strengths do not correlate with changes in the $v_{\mathrm{CO}}$ and follow the trends shown in Fig. 9. However, for adsorption on hydrated Pt, QTAIM shows internal $\mathrm{CO}_{\text {ads }}$ bond strengthen and $\mathrm{C}-\mathrm{Pt}$ bond weaken, along with increased $\mathrm{CO}$ coverage, and are in agreement with changes in the $v_{\mathrm{CO}}$ and $v_{\mathrm{CPt}}$.

Table I shows the $\mathrm{CO}$ contributions to the tilde-type orbital/bands, and outputs from the $5 \sigma$ donation- $2 \pi^{*}$ backdonation and extended $\pi-\sigma$ models for $\mathrm{CO} / \mathrm{Pt}$ at various coverages, with and without hydration (in units of $e$ ). For adsorption on hydrated $\mathrm{Pt}$, increased $\mathrm{CO}$ coverage, strengthens the $\mathrm{C}-\mathrm{O} \tilde{\pi}$-system (Table I, $1 \tilde{\pi}+d_{\tilde{\pi}}-2 \tilde{\pi}^{*}$ values). Additional calculations show that increased CO coverage on hydrated Pt increases the $4 \tilde{\sigma}$ polarization towards carbon and $5 \tilde{\sigma}$ towards oxygen, thus strengthening the $\mathrm{CO}_{\text {ads }}$ (i.e., stronger $\mathrm{C}-\mathrm{O} \tilde{\sigma}-$ system), whereas there is no clear trend described from the changes of overall CO contributions to the $\tilde{\sigma}$-system. The combined effect of the charges and polarization changes in $\mathrm{C}-\mathrm{O} \tilde{\sigma}$-system is described by the changes in the QTAIM $\lambda_{3}$ eigenvalue: Here, the increased $\lambda_{3}$ eigenvalue (at the $\mathrm{C}-\mathrm{O}$ bond critical point) is indicative of the $\tilde{\sigma}$-system being more bonding.

Figure 10 shows the $\mathrm{R}_{\mathrm{O}-\mathrm{bcp}}$ and the $\left|\lambda_{3}\right|$ at the VSCC carbon non-bonding location $(3,-3)$ vs. $\mathrm{CO}$ atop adsorption on hydrated and dry Pt at 1/9ML, 1/3ML, and 5/9 ML. At the $1 / 9$ ML CO coverage, the absence of hydration increases the
TABLE I. CO contributions to the tilde-type orbital/bands, and outputs from the $5 \sigma$ donation- $2 \pi^{*}$ backdonation and extended $\pi-\sigma$ models for CO/Pt at $1 / 9 \mathrm{ML}, 1 / 3 \mathrm{ML}$, and $5 / 9 \mathrm{ML}$ CO coverages with and without 12 interacting waters per unit cell. The Pt top layer was relaxed during geometry optimizations. Values in parentheses refer to the hydrated case. Rows for the 5/9 ML CO coverage refers to atop, bridge, and 3-fold sites values. The higher values on the both phenomenological models are indicative of weaker internal $\mathrm{CO}_{\mathrm{ads}}$ bond.

\begin{tabular}{|c|c|c|c|}
\hline \multirow[b]{2}{*}{ CO orbital/band } & \multicolumn{3}{|c|}{ CO coverage } \\
\hline & $1 / 9 \mathrm{ML}$ & $1 / 3 \mathrm{ML}$ & 5/9 ML \\
\hline $4 \tilde{\sigma}$ & $1.653(1.728)$ & $1.678(1.671)$ & $\begin{array}{l}1.668(1.655) \\
1.655(1.643) \\
1.763(1.790)\end{array}$ \\
\hline $5 \tilde{\sigma}$ & $1.590(1.601)$ & $1.581(1.582)$ & $\begin{array}{l}1.620(1.627) \\
1.696(1.683) \\
1.700(1.631)\end{array}$ \\
\hline$d_{\tilde{\sigma}}$ & $0.317(0.326)$ & $0.298(0.322)$ & $\begin{array}{c}0.354(0.364) \\
0.409(0.423) \\
0.507(0.542)\end{array}$ \\
\hline $1 \tilde{\pi}$ & $3.531(3.521)$ & $3.559(3.544)$ & $\begin{array}{l}3.455(3.489) \\
2.850(2.677) \\
2.555(2.464)\end{array}$ \\
\hline$d_{\tilde{\pi}}$ & $0.548(0.419)$ & $0.554(0.502)$ & $\begin{array}{c}0.611(0.551) \\
1.054(1.031) \\
1.126(1.337)\end{array}$ \\
\hline $2 \tilde{\pi}^{*}$ & $0.301(0.537)$ & $0.285(0.346)$ & $\begin{array}{r}0.291(0.280) \\
0.800(0.788) \\
0.905(0.854)\end{array}$ \\
\hline \multicolumn{4}{|l|}{ Models } \\
\hline $5 \sigma-2 \pi *$ & $1.891(2.138)$ & $1.866(1.929)$ & $\begin{array}{c}1.912(1.908) \\
2.496(2.471) \\
2.605(2.486)\end{array}$ \\
\hline Extended $\pi-\sigma$ & $2.085(2.366)$ & $2.077(2.140)$ & $\begin{array}{c}2.122(2.114) \\
2.658(2.640) \\
2.876(2.830)\end{array}$ \\
\hline
\end{tabular}

$\left|\lambda_{3}\right|$ value at the VSCC carbon non-bonding location, which is in agreement with the changes in the $\tilde{\sigma}$ system polarization between adsorption on dry and hydrated Pt. At 1/3ML, and 5/9 ML coverages, no significant changes are observed in the $\left|\lambda_{3}\right|$ value at the VSCC carbon non-bonding location [Fig. 10(b)].

On hydrated $\mathrm{Pt}$, both the $5 \sigma$ donation $-2 \pi^{*}$ backdonation and the extended $\pi-\sigma$ models show stronger internal $\mathrm{CO}_{\mathrm{ads}}$ bond with increasing CO coverage (Table I). These models are consistent with calculated changes in the QTAIM properties at the $\mathrm{C}-\mathrm{O}$ critical points [Figs. 9(a), 9(c), and 9(e), gray symbols and lines] and the upshifts of the $v_{\mathrm{CO}}$ [Fig. 8(b), gray symbols and lines].

However, in the absence of hydration, both models show that the internal $\mathrm{CO}_{\mathrm{ads}}$ bond strength follows the changes in the $\mathrm{C}-\mathrm{O}$ COOP [Fig. 8(c), blue symbols and lines]. We examine the case of increased CO coverage from 1/9 ML to 1/3 $\mathrm{ML}$, where QTAIM properties show that internal $\mathrm{CO}_{\text {ads }}$ bond weaken, in contrast with the $v_{\mathrm{CO}}$ upshift [Fig. 8(b), blue symbols and lines]. Recall that, in this case, $\mathrm{C}-\mathrm{O}$ and the $v_{\mathrm{CO}}$ do not follow the Badger rule [Figs. 8(a) and 8(b)]. Table I shows that both models predict increased $\mathrm{C}-\mathrm{O} \tilde{\pi}$-system bonding 


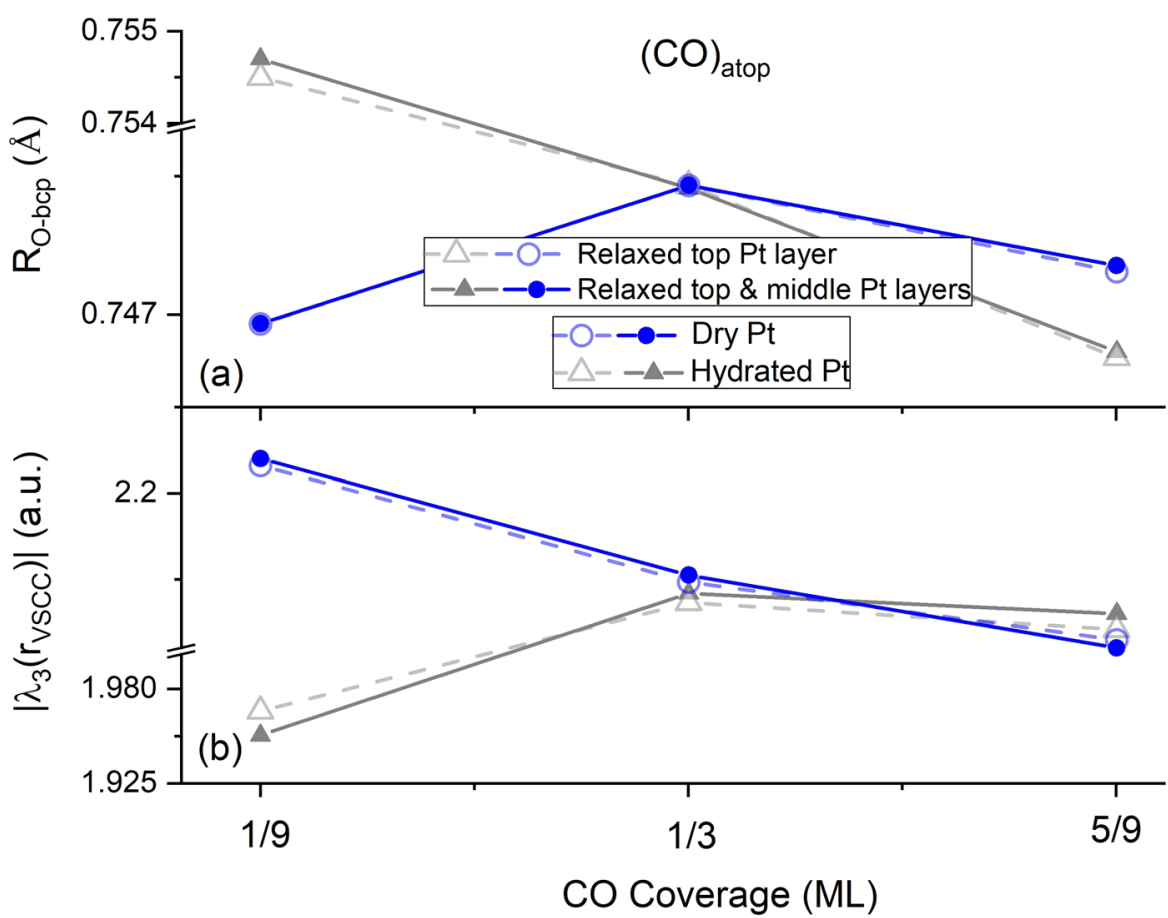

FIG. 10. QTAIM calculated properties vs. CO atop coverage on dry (blue circles) and hydrated (gray triangles, 12 water) Pt. Relaxed top substrate (hollow shapes); Both top and middle substrate layers relaxed (solid shapes): (a) $\mathrm{R}_{\mathrm{O}-\mathrm{bcp}}$ and (b) carbon non-bonding valence shell charge concentration [VSCC $(3,-3)]\left|\lambda_{3}\right|$ value. via decreased $2 \pi^{*}$ charge, for adsorption on dry Pt. For the extended $\pi-\sigma$ model, increased $\mathrm{C}-\mathrm{O}$ bonding due to changes in the $\tilde{\pi}$-system more than offsets the $\mathrm{C}-\mathrm{O}$ bond weakening due to changes in the $\tilde{\sigma}$-system, the latter agreeing with the changes in the QTAIM $\lambda_{3}$ eigenvalue at the $\mathrm{C}-\mathrm{O}$ bond critical point (Fig. S2c). Therefore, in the absence of a negative correlation between bond lengths and stretching frequencies, phenomenological models that use charge contributions to the adsorbate/molecular orbitals as inputs, are not consistent with QTAIM calculations of the internal $\mathrm{CO}_{\mathrm{ads}}$ bond strengths. However, the QTAIM non-zero eigenvalues $\lambda_{1}$, $\lambda_{2}$, and $\lambda_{3}$ can serve as substitutes for the adsorbate orbital information since they are directly correlated with changes in the $\tilde{\sigma}$ - and $\tilde{\pi}$-systems and their summation is equal to the value of $\nabla^{2} \rho(\vec{r})$ at the bond critical points. This statement applies to all cases and provides a basis set and method independent approach for $\mathrm{C}-\mathrm{O}$ and $\mathrm{C}-\mathrm{Pt}$ bond strength assessment.

\section{Bridge and 3-fold Pt sites: 5/9 ML CO co-adsorbed with water}

The internal $\mathrm{CO}_{\mathrm{ads}}$ and $\mathrm{C}-\mathrm{Pt}$ bonds at bridge and 3fold sites at 5/9 ML CO coverage are contrasted with atop adsorption. Figure 11 shows changes in the $v_{\mathrm{CO}}, v_{\mathrm{CPt}}$, the respective bond lengths, $\mathrm{E}_{\mathrm{ads}}$, and the $|\mathrm{H} / \rho(\vec{r})|$ at bond critical points of atop, bridge, and 3-fold $\mathrm{CO}_{\text {ads }}$ on dry (blue) and hydrated (gray) Pt (12 waters). Whether dry or hydrated, the $v_{\mathrm{CO}}$ and $v_{\mathrm{CPt}}$ systematically downshift as the $\mathrm{C}$ to Pt coordination increases from atop to bridge to 3 -fold, concomitant with an increase in corresponding bond lengths [Figs. 11(a) and 11(b), squares and rhombus]. These trends are consistent with $v_{\mathrm{CO}}$ DFT calculations by Deshlahra et al. (Ref. 89) and Shan et al. (Ref. 90) (dry calculations), and observed spectra (hydrated Pt, atop and bridge sites). ${ }^{108}$ Thus, our $v_{\mathrm{CO}}$ and $v_{\mathrm{CPt}}$ downshifts confirm internal $\mathrm{CO}_{\mathrm{ads}}$ and $\mathrm{C}-\mathrm{Pt}$ bond weakening with increased $\mathrm{C}$ to $\mathrm{Pt}$ coordination: This is consistent with decreased QTAIM $|\mathrm{H} / \rho(\vec{r})|$ at C-O and C-Pt bond critical points and bond strengths negatively correlated to coordination number [Figs. 11(c) and 11(d)]. The negative correlation is further supported by changes in the $\rho(\vec{r})$ and $\nabla^{2} \rho(\vec{r})$ at the above bond critical points (Fig. S3) and by the $\mathrm{C}-\mathrm{O}$ and $\mathrm{C}-\mathrm{Pt}$ COOP (Fig. S4).

For hydrated and dry $\mathrm{Pt}$, the internal $\mathrm{CO}_{\mathrm{ads}}$ and $\mathrm{C}-\mathrm{Pt}$ bond-strength dependence on the $\mathrm{C}$ to Pt coordination number was examined by QTAIM and $\mathrm{CO}_{\text {ads }}$ orbital analyses. The $\left|\lambda_{\mathrm{i}}\right|(\mathrm{i}=1,2,3)$ eigenvalues at the $\mathrm{C}-\mathrm{O}$ and $\mathrm{C}-\mathrm{Pt}$ bond critical points all decrease with increased coordination, in contrast to atop adsorptions (3.1 and 3.2) at various CO coverages and hydrations. The diminishing of all $\left|\lambda_{\mathrm{i}}\right|$ values at the $\mathrm{C}-\mathrm{Pt}$ bond critical point, and the $\left|\lambda_{3}\right|$ at the VSCC carbon non-bonding location (Fig. S5), are attributed to an increase in bond critical points per $\mathrm{Pt}$, as the $\mathrm{C}$ to $\mathrm{Pt}$ coordination increases.

Both $\tilde{\sigma}$ - and $\tilde{\pi}$-systems weaken the internal $\mathrm{CO}_{\text {ads }}$ and $\mathrm{C}-$ $\mathrm{Pt}$ bonds as the $\mathrm{C}-\mathrm{Pt}$ coordination increases. For $\mathrm{CO}_{\text {ads }}$ atop vs. bridge and three-fold sites, the $4 \tilde{\sigma}$ and $5 \tilde{\sigma}$ orbital polarizations increase towards carbon and oxygen, respectively. This strengthens both the internal $\mathrm{CO}_{\mathrm{ads}}$ bond and the $\mathrm{C}-\mathrm{Pt}$ bond 


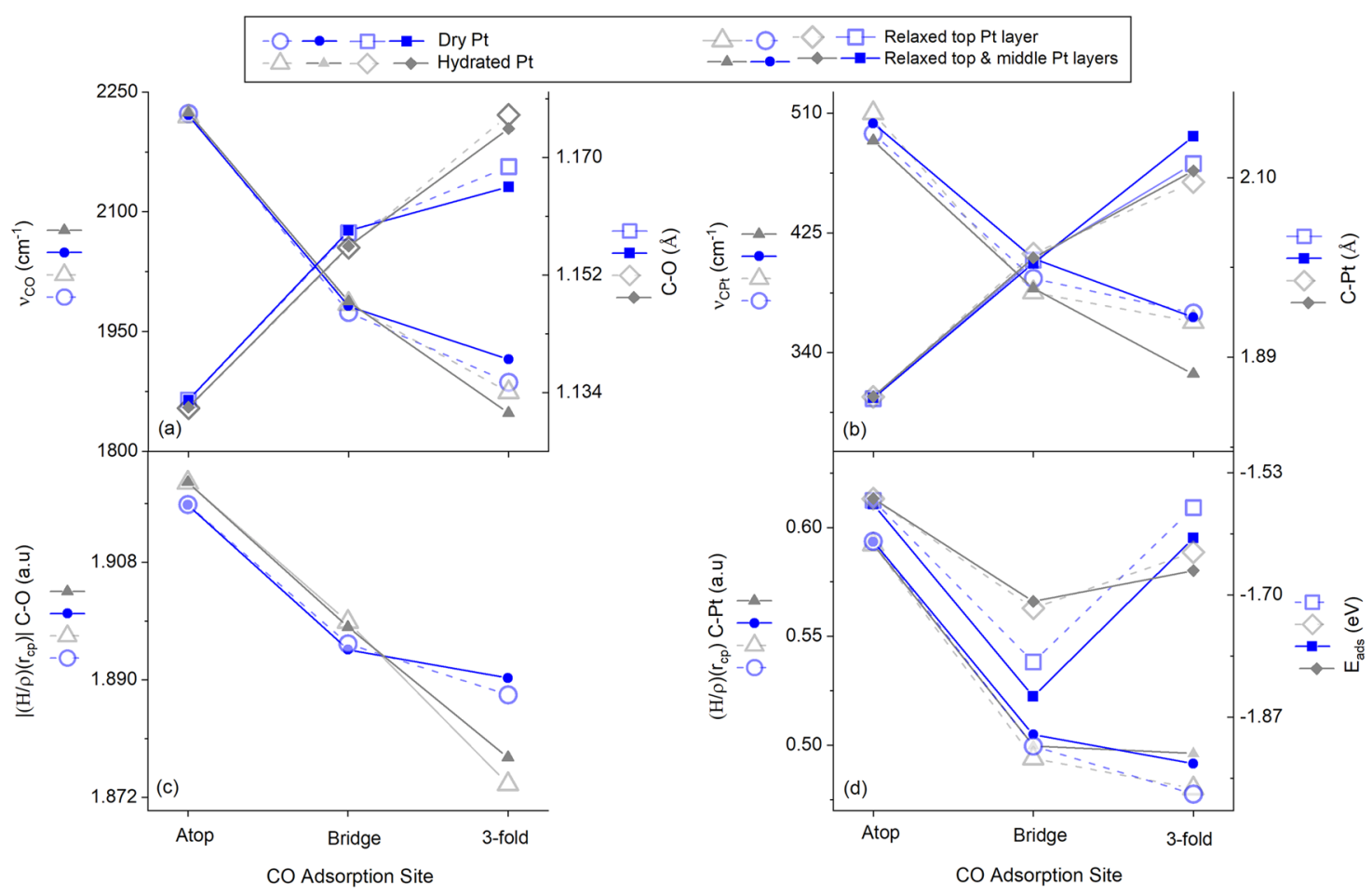

FIG. 11. DFT and QTAIM properties for $\mathrm{CO}_{\text {ads }}$ atop, bridge, and three-fold at 5/9 ML CO. Dry (blue), hydrated (gray, 12 water), relaxed Pt top layer (hollow shapes) and relaxed top and middle Pt layers (solid shapes): (a) $v_{\mathrm{CO}}$ (circles and triangles) and $\mathrm{C}-\mathrm{O}$ (squares and rhombus) (b) $v_{\mathrm{CPt}}$ (circles and triangles) and C-Pt (squares and rhombus), (c) $(\mathrm{H} / \rho)(\vec{r})$ at the $\mathrm{C}-\mathrm{O}$ critical points (circles and triangles), and $(\mathrm{d})(\mathrm{H} / \rho)(\vec{r})$ at the $\mathrm{C}-\mathrm{Pt}$ critical points (circles and triangles) and $\mathrm{E}_{\text {ads }}$ (squares and rhombus).

( $4 \tilde{\sigma}$ and $5 \tilde{\sigma}$ orbitals are bonding to the metal). However, the increased $\mathrm{CO}$ contributions to the entire $\tilde{\sigma}$-system (mostly due increased CO contributions to the $d_{\tilde{\sigma}}$-band, Table I) more than offsets bond strengthening due to changes in the $4 \tilde{\sigma}$ and $5 \tilde{\sigma}$ polarizations. The decrease of the $\lambda_{3}$ eigenvalue, at the $\mathrm{C}-\mathrm{O}$ bond critical point, as the $\mathrm{C}$ to $\mathrm{Pt}$ coordination increases, is consistent with $\mathrm{C}-\mathrm{O} \sigma$ bond weakening.

The overall $\mathrm{C}-\mathrm{O} \tilde{\pi}$-system weakens the bond with increased coordination: The $\mathrm{CO}$ contributions to the $2 \tilde{\pi}^{*}-$ and $d_{\tilde{\pi}}$-bands increase and the CO contribution to the $1 \tilde{\pi}$ orbital decreases. In summary, both phenomenological models show that increased $\mathrm{C}$ to $\mathrm{Pt}$ coordination weakens the internal $\mathrm{CO}_{\text {ads }}$ bond (Table I). The $\mathrm{C}-\mathrm{Pt}$ bond also weakens as $\mathrm{CO}$ contributions to the C-Pt antibonding bands (i.e., $d_{\tilde{\sigma}}$ and $d_{\tilde{\pi}}$ ) increases. All the above are consistent with decreased $\left|\lambda_{1}\right|$ and $\left|\lambda_{2}\right|$ eigenvalues at both the $\mathrm{C}-\mathrm{O}$ and $\mathrm{C}-\mathrm{Pt}$ bond critical points.

\section{CONCLUSIONS}

\section{A. $\mathrm{CO}_{\text {ads }}$ at low coverage}

At low $\mathrm{CO}_{\text {ads }}$ coverage, water co-adsorption weakens the sums of the $\mathrm{C}-\mathrm{O} \tilde{\sigma}$ - and $\tilde{\pi}$-system orbitals. The resulting internal $\mathrm{CO}_{\mathrm{ads}}$ bond weakening is concomitant with $\mathrm{C}-\mathrm{Pt}$ bond strengthening. These co-adsorption net-effects increase with hydration and are consistent with observed shifts on $v_{\mathrm{CO}}$ and $v_{\mathrm{CPt}}$, and $\rho(\vec{r}), \nabla^{2} \rho(\vec{r})$, and $\mathrm{H} / \rho(\vec{r})$ evaluated at the bond critical points. We correlated the $\rho(\vec{r})$ Hessian non-zero eigenvalues $\lambda_{\mathrm{i},}(\mathrm{i}=1,2,3)$ with changes in the $\tilde{\pi}$ - and $\tilde{\sigma}$-system. Specifically, decreases in the $\left|\lambda_{1}\right|$ and $\left|\lambda_{2}\right|$ correspond to weaker $\mathrm{C}-\mathrm{O}$ $\pi$ bonding and decreases in the $\lambda_{3}$ (all at the $\mathrm{C}-\mathrm{O}$ bond critical point) to weaker $\mathrm{C}-\mathrm{O} \sigma$ bonding. The QTAIM view of internal $\mathrm{CO}_{\mathrm{ads}}$ bond weakening, resulting from Pt surface hydration, is consistent with the $5 \sigma$ donation $-2 \pi^{*}$ backdonation and the extended $\pi-\sigma$ model.

\section{B. $\mathrm{CO}_{\text {ads }}$ atop at higher coverage}

Increasing $\mathrm{CO}$ coverage eventually precludes water coadsorption, while strengthening the internal bond of atop $\mathrm{CO}_{\text {ads }}$ at the expense of the $\mathrm{C}-\mathrm{Pt}$ bond strength. This is consistent with the classic inverse relationship of atop $\mathrm{C}-\mathrm{O}$ to $\mathrm{C}-\mathrm{Pt}$ stretching frequencies and with QTAIM. However, for $\mathrm{CO}_{\mathrm{ads}}$ on dry $\mathrm{Pt}$, the atop $\mathrm{C}-\mathrm{O}$ bond lengths and their $v_{\mathrm{CO}}$ values are not negatively correlated. Therefore, increased $v_{\mathrm{CO}}$ values do not always correlate to stronger bonds as might be intuitively expected (Ref. 109).

In general, the $\rho(\vec{r}), \nabla^{2} \rho(\vec{r})$, and $\mathrm{H} / \rho(\vec{r})$ at bond critical points are negatively correlated to bond lengths. In this work, when DFT calculated bond lengths and stretching frequencies 
are not negatively correlated, the phenomenological models cannot be reconciled with QTAIM results. However, because of the direct relationship between the $\tilde{\pi}$ - and the $\tilde{\sigma}$-orbitals and the $\lambda_{\mathrm{i}}$ at the $\mathrm{C}-\mathrm{O}$ bond critical points, the $\lambda_{\mathrm{i}}$ values can be used as inputs to phenomenological models to obtain an accurate description of how bond strengths vary with coverages. This demonstrates, as a highlight of this work, a powerful synergy between QTAIM and phenomenological models.

\section{C. $\mathrm{CO}_{\text {ads }}$ bridge and 3-fold vs. atop}

Both QTAIM and $\mathrm{CO}_{\text {ads }}$ orbital analyses confirm weakening of both the internal $\mathrm{C}_{\mathrm{ads}}$ and $\mathrm{C}-\mathrm{Pt}$ bonds with increased $\mathrm{Pt}$ coordination, in agreement with spectroscopic observations, and the weakening of both the $\tilde{\pi}$ - and the $\tilde{\sigma}$-systems. The above are all consistent with decreased $\lambda_{\mathrm{i}}$ at $\mathrm{C}-\mathrm{O}$ and $\mathrm{C}-\mathrm{Pt}$ bond critical points. The $\mathrm{CO}_{\mathrm{ads}}$ orbital analyses show weakening of the $\mathrm{C}-\mathrm{Pt}$ bond due to increased $\mathrm{CO}$ contributions to the $\mathrm{C}-\mathrm{Pt}$ antibonding $d_{\tilde{\sigma}}$ and $d_{\tilde{\pi}}$-bands. These effects more than offset the $\mathrm{C}-\mathrm{Pt}$ bonding, caused by the remaining orbitals/bands of the $\tilde{\pi}$ - and the $\tilde{\sigma}$-systems.

These conclusions can be extended to other similar systems. Augmentation of the extended $\pi-\sigma$ model with QTAIM provides a computational method and basis set independent technique for analyzing adsorption.

\section{SUPPLEMENTARY MATERIAL}

See supplementary material for calculated $v_{\mathrm{CO}}$, alternative expressions for CO contributions to the $\tilde{\sigma}$-system relative to number of integrating waters, and additional QTAIM properties at atop, bridge, and three-fold sites.

\section{ACKNOWLEDGMENTS}

This work was partially supported by the ARO Grant No. W911NF-17-1-0557.

\section{REFERENCES}

${ }^{1}$ J. W. T. Grubb, Google patent US2913511A (1959).

${ }^{2}$ S. Gilman, J. Phys. Chem. A 68, 70 (1964).

${ }^{3}$ T. Frelink, W. Visscher, and J. A. R. van Veen, Surf. Sci. 335, 353 (1995).

${ }^{4}$ N. Loupe, J. Doan, and E. S. Smotkin, Catal. Today 283, 11 (2017).

${ }^{5}$ S. E. Evarts, I. Kendrick, B. L. Wallstrom, T. Mion, M. Abedi, N. Dimakis, and E. S. Smotkin, ACS Catal. 2, 701 (2012).

${ }^{6}$ B. Hammer, Y. Morikawa, and J. K. Nørskov, Phys. Rev. Lett. 76, 2141 (1996).

${ }^{7}$ N. Dimakis, H. Iddir, R. R. Diaz-Morales, R. Liu, G. Bunker, E.-H. Chung, and E. S. Smotkin, J. Phys. Chem. B 109, 1839 (2005).

${ }^{8}$ G. Blyholder, J. Phys. Chem. 68, 2772 (1964).

${ }^{9} \mathrm{P}$. Bennich, T. Wiell, O. Karis, M. Weinelt, N. Wassdahl, A. Nilsson, M. Nyberg, L. G. M. Pettersson, J. Stöhr, and M. Samant, Phys. Rev. B 57, 9274 (1998).

${ }^{10}$ A. Föhlisch, M. Nyberg, J. Hasselström, O. Karis, L. G. M. Pettersson, and A. Nilsson, Phys. Rev. Lett. 85, 3309 (2000).

${ }^{11}$ A. Föhlisch, M. Nyberg, P. Bennich, L. Triguero, J. Hasselström, O. Karis, L. G. M. Pettersson, and A. Nilsson, J. Chem. Phys. 112, 1946 (2000).

${ }^{12}$ A. Föhlisch, J. Hasselström, P. Bennich, N. Wassdahl, O. Karis, A. Nilsson, L. Triguero, M. Nyberg, and L. Pettersson, Phys. Rev. B 61, 16229 (2000).
${ }^{13}$ A. Nilsson, M. Weinelt, T. Wiell, P. Bennich, O. Karis, N. Wassdahl, J. Stohr, and M. G. Samant, Phys. Rev. Lett. 78, 2847 (1997).

${ }^{14}$ N. Dimakis, M. Cowan, G. Hanson, and E. S. Smotkin, J. Phys. Chem. C 113, 18730 (2009).

${ }^{15}$ N. Dimakis, T. Mion, and E. S. Smotkin, J. Phys. Chem. C 116, 21447 (2012).

${ }^{16}$ N. Dimakis, N. E. Navarro, T. Mion, and E. S. Smotkin, J. Phys. Chem. C 118, 11711 (2014).

${ }^{17}$ N. Dimakis, F. A. Flor, N. E. Navarro, A. Salgado, and E. S. Smotkin, J. Phys. Chem. C 120, 10427 (2016).

${ }^{18}$ J. W. Russell, J. Overend, K. Scanlon, M. Severson, and A. Bewick, J. Phys. Chem. 86, 3066 (1982).

${ }^{19}$ C. S. Kim, W. J. Tornquist, and C. Korzeniewski, J. Chem. Phys. 101, 9113 (1994).

${ }^{20}$ C. S. Kim and C. Korzeniewski, Anal. Chem. 69, 2349 (1997).

${ }^{21}$ G. Blyholder, J. Vac. Sci. Technol. 11, 865 (1974).

${ }^{22}$ F. Illas, S. Zurita, A. Marquez, and J. Rubio, Surf. Sci. 376, 279 (1997).

${ }^{23}$ G. Rangelov, N. Memmel, E. Bertel, and V. Dose, Surf. Sci. 251, 965 (1991).

${ }^{24}$ P. Ferrari, L. M. Molina, V. E. Kaydashev, J. A. Alonso, P. Lievens, and E. Janssens, Angew. Chem. 128, 11225 (2016).

${ }^{25}$ L. Foppa, C. Copéret, and A. Comas-Vives, J. Am. Chem. Soc. 138, 16655 (2016).

${ }^{26}$ W. T. Cahyanto, W. Widanarto, G. Shukri, and H. Kasai, Phys. Scr. 91, 025803 (2016).

${ }^{27}$ Y.-W. Huang and S.-L. Lee, Chem. Phys. Lett. 530, 64 (2012).

${ }^{28}$ M. Jabłoński and M. Palusiak, J. Phys. Chem. A 114, 2240 (2010).

${ }^{29} \mathrm{CRYSPLOT}$, an online tool to visualize computed properties of periodic systems, see http:/ /crysplot.crystalsolutions.eu/index.html.

${ }^{30}$ D. Vega and D. Almeida, J. Comput. Methods Sci. Eng. 14, 131 (2014).

${ }^{31}$ R. F. W. Bader, P. J. MacDougall, and C. D. H. Lau, J. Am. Chem. Soc. 106, 1594 (1984).

${ }^{32}$ Y. Aray and J. Rodríguez, Can. J. Chem. 74, 1014 (1996).

${ }^{33}$ Y. Aray and J. Rodriguez, Surf. Sci. 405, L532 (1998).

${ }^{34}$ Y. Aray, J. Rodriguez, J. Rivero, and D. Vega, Surf. Sci. 441, 344 (1999).

${ }^{35}$ B. Rees and A. Mitschler, J. Am. Chem. Soc. 98, 7918 (1976).

${ }^{36}$ P. Macchi, D. M. Proserpio, and A. Sironi, J. Am. Chem. Soc. 120, 13429 (1998).

${ }^{37}$ P. Macchi and A. Sironi, Coord. Chem. Rev. 238, 383 (2003).

${ }^{38}$ K. Morokuma, J. Chem. Phys. 55, 1236 (1971).

${ }^{39}$ K. Kitaura and K. Morokuma, Int. J. Quantum Chem. 10, 325 (1976).

${ }^{40}$ P. S. Bagus, K. Hermann, and C. W. Bauschlicher, J. Chem. Phys. 80, 4378 (1984).

${ }^{41}$ P. S. Bagus, K. Hermann, and C. W. Bauschlicher, J. Chem. Phys. 81, 1966 (1984).

${ }^{42}$ E. D. Glendening and A. Streitwieser, J. Chem. Phys. 100, 2900 (1994).

${ }^{43}$ E. D. Glendening, J. Am. Chem. Soc. 118, 2473 (1996).

${ }^{44}$ E. D. Glendening, J. Phys. Chem. A 109, 11936 (2005).

${ }^{45}$ R. Z. Khaliullin, E. A. Cobar, R. C. Lochan, A. T. Bell, and M. Head-Gordon, J. Phys. Chem. A 111, 8753 (2007).

${ }^{46}$ P. R. Horn, E. J. Sundstrom, T. A. Baker, and M. Head-Gordon, J. Chem. Phys. 138, 134119 (2013).

${ }^{47}$ M. Raupach and R. Tonner, J. Chem. Phys. 142, 194105 (2015).

${ }^{48}$ P. S. Bagus and G. Pacchioni, Surf. Sci. 278, 427 (1992).

${ }^{49}$ P. S. Bagus, C. J. Nelin, and C. W. Bauschlicher, J. Vac. Sci. Technol., A 2, 905 (1984).

${ }^{50}$ D. Curulla, A. Clotet, J. M. Ricart, and F. Illas, J. Phys. Chem. B 103, 5246 (1999).

${ }^{51}$ C. N. Hernańdez and C. M. Zicovich-Wilson, J. Chem. Phys. 124, 194105 (2006).

${ }^{52}$ G. Pacchioni, T. Minerva, and P. S. Bagus, Surf. Sci. 275, 450 (1992).

${ }^{53}$ P. Hohenberg and W. Kohn, Phys. Rev. 136, B864 (1964).

${ }^{54}$ W. Kohn and L. J. Sham, Phys. Rev. 140, A1133 (1965).

${ }^{55}$ R. S. Mulliken, J. Chem. Phys. 23, 1833 (1955). 
${ }^{56}$ D. Ogletree, M. Van Hove, and G. Somorjai, Surf. Sci. 173, 351 (1986).

${ }^{57}$ G. S. Blackman, M. L. Xu, D. F. Ogletree, M. A. Van Hove, and G. A. Somorjai, Phys. Rev. Lett. 61, 2352 (1988).

${ }^{58}$ H. Hopster and H. Ibach, Surf. Sci. 77, 109 (1978).

${ }^{59} \mathrm{H}$. Steininger, S. Lehwald, and H. Ibach, Surf. Sci. 123, 264 (1982).

${ }^{60}$ B. Hayden, K. Kretzschmar, A. Bradshaw, and R. Greenler, Surf. Sci. 149, 394 (1985).

${ }^{61}$ M.-L. Bocquet and P. Sautet, Surf. Sci, 360, 128 (1996).

${ }^{62}$ See http: / / www.jmol.org for Jmol, an open-sourse Java viewer for chemical structures in 3D.

${ }^{63}$ P. J. Feibelman, B. Hammer, J. K. Nørskov, F. Wagner, M. Scheffler, R. Stumpf, R. Watwe, and J. Dumesic, J. Phys. Chem. B 105, 4018 (2001).

${ }^{64}$ R. Dovesi, V. Saunders, C. Roetti, R. Orlando, C. Zicovich-Wilson, F. Pascale, B. Civalleri, K. Doll, N. Harrison, and I. Bush, CRYSTAL14 User's Manual (University of Torino, Torino, 2014).

${ }^{65}$ R. Dovesi, R. Orlando, A. Erba, C. M. Zicovich-Wilson, B. Civalleri, S. Casassa, L. Maschio, M. Ferrabone, M. De La Pierre, and P. D'Arco, Int. J. Quantum Chem. 114, 1287 (2014).

${ }^{66} \mathrm{M}$. Ernzerhof and G. E. Scuseria, J. Chem. Phys. 110, 5029 (1999).

${ }^{67}$ C. Adamo and V. Barone, J. Chem. Phys. 110, 6158 (1999).

${ }^{68}$ F. Pascale, C. M. Zicovich-Wilson, F. Lopez Gejo, B. Civalleri, R. Orlando, and R. Dovesi, J. Comput. Chem. 25, 888 (2004).

${ }^{69}$ D. Andrae, U. Haeussermann, M. Dolg, H. Stoll, and H. Preuss, Theor. Chim. Acta 77, 123 (1990).

${ }^{70}$ See http:/ / www.uni-stuttgart.de/theochem for Stuttgart/Cologne energyconsistent (ab initio) pseudopotentials suitable for DFT calculations.

${ }^{71}$ K. Doll, Surf. Sci. 573, 464 (2004).

${ }^{72}$ M. F. Peintinger, D. V. Oliveira, and T. Bredow, J. Comput. Chem. 34, 451 (2013).

${ }^{73}$ H. J. Monkhorst and J. D. Pack, Phys. Rev. B 13, 5188 (1976).

${ }^{74} \mathrm{G}$. Gilat and L. Raubenheimer, Phys. Rev. 144, 390 (1966).

${ }^{75}$ G. Gilat, J. Comput. Phys. 10, 432 (1972).

${ }^{76}$ R. Hoffmann, Rev. Mod. Phys. 60, 601 (1988).

${ }^{77}$ R. Dovesi, V. R. Saunders, C. Roetti, C. M. Zicovich-Wilson, F. Pascale, B. Civalleri, K. Doll, N. M. Harrison, I. J. Bush, P. D'Arco, M. Llunell, M. Causà, Y. Noël, L. Maschio, R. Orlando, A. Erba, M. Rérat, and S. Casassa, CRYSTAL17 User's Manual (University of Torino, Torino, 2017).

${ }^{78} \mathrm{C}$. Stampfl and M. Scheffler, Phys. Rev. B 65, 155417 (2002).

${ }^{79}$ S. F. Boys and F. Bernardi, Mol. Phys. 19, 553 (1970).

${ }^{80}$ F. B. Van Duijneveldt, J. G. van Duijneveldt-van de Rijdt, and J. H. van Lenthe, Chem. Rev. 94, 1873 (1994).

${ }^{81}$ C. Gatti, User's Manual (CNR-CSRSRC, Milano, 1996).
${ }^{82}$ C. Gatti, V. Saunders, and C. Roetti, J. Chem. Phys. 101, 10686 (1994).

${ }^{83} \mathrm{C}$. Gatti, Z. Kristallogr. Cryst. Mater. 220, 399 (2005).

${ }^{84} \mathrm{M}$. T. Ruggiero, A. Erba, R. Orlando, and T. M. Korter, Phys. Chem. Chem. Phys. 17, 31023 (2015).

${ }^{85}$ R. Dronskowski and P. E. Bloechl, J. Phys. Chem. 97, 8617 (1993).

${ }^{86}$ A. Grechnev, R. Ahuja, and O. Eriksson, J. Phys.: Condens. Matter 15, 7751 (2003).

${ }^{87}$ I. Dabo, A. Wieckowski, and N. Marzari, J. Am. Chem. Soc. 129, 11045 (2007).

${ }^{88}$ M. T. M. Koper, T. E. Shubina, and R. A. van Santen, J. Phys. Chem. B 106, 686 (2002).

${ }^{89}$ P. Deshlahra, J. Conway, E. E. Wolf, and W. F. Schneider, Langmuir 28, 8408 (2012).

${ }^{90}$ B. Shan, Y. Zhao, J. Hyun, N. Kapur, J. B. Nicholas, and K. Cho, J. Phys. Chem. C 113, 6088 (2009).

${ }^{91}$ R. Liu, H. Iddir, Q. B. Fan, G. Y. Hou, A. L. Bo, K. L. Ley, E. S. Smotkin, Y. E. Sung, H. Kim, S. Thomas, and A. Wieckowski, J. Phys. Chem. B 104, 3518 (2000).

${ }^{92}$ S. C. Chang and M. J. Weaver, J. Chem. Phys. 92, 4582 (1990).

${ }^{93} \mathrm{~K}$. Yoshimi, M.-B. Song, and M. Ito, Surf. Sci. 368, 389 (1996).

${ }^{94}$ J. A. Steckel, A. Eichler, and J. Hafner, Phys. Rev. B 68, 085416 (2003).

${ }^{95}$ R. M. Badger, J. Chem. Phys. 2, 128 (1934).

${ }^{96}$ R. M. Badger, J. Chem. Phys. 3, 710 (1935).

97J. Cioslowski, G. Liu, and R. A. M. Castro, Chem. Phys. Lett. 331, 497 (2000).

${ }^{98}$ S.-C. Chang and M. J. Weaver, Surf. Sci. 238, 142 (1990).

${ }^{99} \mathrm{M}$. W. Severson, C. Stuhlmann, I. Villegas, and M. J. Weaver, J. Chem. Phys. 103, 9832 (1995).

${ }^{100} \mathrm{C}$. Korzeniewski, V. Climent, and J. M. Feliu, in Electroanalytical Chemistry, edited by C. Zoski and A. J. Bard (Taylor \& Francis, 2012), p. 75.

${ }^{101} \mathrm{C}$. Korzeniewski, in Interfacial Electrochemistry, edited by A. Wieckowski (Marcel Dekker, Inc., New York, 1999), p. 345.

${ }^{102}$ S. C. Chang and M. J. Weaver, J. Phys. Chem. 95, 5391 (1991).

${ }^{103}$ C. Korzeniewski and M. W. Severson, Spectrochim. Acta, Part A 51, 499 (1995).

${ }^{104}$ H. Ueba, Surf. Sci. 188, 421 (1987).

${ }^{105}$ D. Loffreda, D. Simon, and P. Sautet, Surf. Sci. 425, 68 (1999).

${ }^{106}$ D. Curulla, A. Clotet, and J. M. Ricart, Surf. Sci. 460, 101 (2000).

${ }^{107}$ M. Kaupp, B. Metz, and H. Stoll, Angew. Chem., Int. Ed. 39, 4607 (2000).

${ }^{108}$ S. D. Ebbesen, B. L. Mojet, and L. Lefferts, Langmuir 22, 1079 (2006).

${ }^{109}$ Y. J. Huang, S. C. Fung, W. E. Gates, and G. B. McVicker, J. Catal. 118, 192 (1989). 